\title{
Aeroservoelastic Testing Of A Sidewall Mounted Free Flying Wind-Tunnel Model
}

\author{
Robert C. Scott, ${ }^{*}$ Travis K. Vetter, ${ }^{\dagger}$ Kevin B. Penning, ${ }^{\ddagger}$ \\ David A. Coulson, ${ }^{\S}$ and Jennifer Heeg $₫$
}

\begin{abstract}
A team comprised of the Air Force Research Laboratory (AFRL), Northrop Grumman, Lockheed Martin, and the NASA Langley Research Center conducted three aeroservoelastic wind-tunnel tests in the Transonic Dynamics Tunnel to demonstrate active control technologies relevant to large, flexible vehicles. In the first of these three tests, a semispan, aeroelastically scaled, wind-tunnel model of a flying wing SensorCraft vehicle was mounted to a force balance to demonstrate gust load alleviation. In the second and third tests, the same wing was mated to a new, multi-degree-of-freedom, sidewall mount. This mount allowed the half-span model to translate vertically and pitch at the wing root, allowing better simulation of the full span vehicle's rigid-body modes. Gust Load Alleviation (GLA) and Body Freedom Flutter (BFF) suppression were successfully demonstrated. The rigid body degrees-of-freedom required that the model be flown in the wind tunnel using an active control system. This risky mode of testing necessitated that a model arrestment system be integrated into the new mount. The safe and successful completion of these free-flying tests required the development and integration of custom hardware and software. This paper describes the many systems, software, and procedures that were developed as part of this effort.
\end{abstract}

\section{Nomenclature}

AEI

AFRL

AOS

ASE

$\mathrm{BFF}$

CG

DAS

DCS

DOF

dSpace1

dSpace2

$\delta_{o}$

FS

GLA

GUI

HiLDA

LAS

LE

LM

LQG

NG

Aeroservoelasticity

Body Freedom Flutter

Center of Gravity

Data Acquisition System

Digital Control System

Degree of Freedom

Flutter Suppression

Gust Load Alleviation

Graphical User Interface

Leading Edge

Lockheed Martin

Northrop Grumman
Aerodynamic Efficiency Improvement

Air Force Research Laboratory

Airstream Oscillating System

DCS for Servo PID loops and WatchDog

DCS for Trim, GLA, \& BFF Suppression

Emergency controller command bias

High Lift over Drag Active Wing

Lift Augmentation System

Linear Quadratic Gaussian

\footnotetext{
*Senior Aerospace Engineer, Aeroelasticity Branch, NASA Langley Research Center, Hampton, VA, AIAA Associate Fellow.

†Senior Engineer, VMS \& Flight Control, Northrop Grumman Corp., El Segundo, CA.

$¥$ Senior Staff Aeronautical Engineer, Advanced Development Programs, Lockheed Martin, Fort Worth, TX.

$\S$ Senior Research Engineer, Analytical Services \& Materials, Inc., Hampton, VA.

ISenior Aerospace Engineer, Aeroelasticity Branch, NASA Langley Research Center, Hampton, VA, AIAA Senior Member.
}

$\begin{array}{ll}\text { PID } & \text { Proportional Integral Derivative } \\ \Theta & \text { Pitch displacement, deg } \\ \dot{\Theta} & \text { Pitch rate, deg/s } \\ \text { PZ } & \text { Vertical position (PZ=0 at centerline), in } \\ \text { RVDT } & \text { Rotary Variable Differential Transducer } \\ \text { Snub! } & \text { Command to engage snubbing system } \\ \text { TDT } & \text { Transonic Dynamic Tunnel } \\ \text { T } & \text { Time, s } \\ \text { TE } & \text { Trailing Edge } \\ \text { VZ } & \text { Vertical velocity, in/s } \\ \text { WatchDog } & \text { Software for triggering Snub! command } \\ \text { WD } & \text { Abbreviation for WatchDog } \\ \text { WoW } & \text { Weight on Wheels }\end{array}$

\section{Introduction}

In the Fall of 2007, the Air Force Research Laboratory (AFRL), Northrop Grumman, Lockheed Martin, and the NASA Langley Research Center, successfully completed the third of a series of three windtunnel tests of an aeroelastically scaled wind-tunnel model of a flying wing SensorCraft vehicle concept. The AFRL SensorCraft is a technology portfolio of advanced sensors, communications links, air vehicle components and propulsion elements. AFRL is pursuing these technology developments for future highaltitude, long-endurance, unmanned surveillance platforms. Two research programs intended to develop technologies relevant to these large, flexible vehicles are the High-Lift-over-Drag Active (HiLDA) Wing and the Aerodynamic Efficiency Improvement (AEI) programs. ${ }^{1}$ The goals of the HiLDA and AEI wind-tunnel 


\begin{tabular}{|c|c|c|c|c|c|c|c|}
\hline & FYO3 & FYO4 & FY05 & FY06 & FY07 & FYO8 & FY09 \\
\hline $\begin{array}{l}\text { HiLDA } \\
\text { T574: NASA } \\
\text { T579: Nothorp Grumman }\end{array}$ & & & & & & & \\
\hline $\begin{array}{l}\text { AEl } \\
\text { T593: Nothoor Grumman } \\
\text { T598: Nothorp Grumman \& } \\
\text { Lockheed Matrin } \\
\text { T6XX: Boeing } \\
\text { T6XX: Boeing }\end{array}$ & & & & & 1 & & | \\
\hline
\end{tabular}

Fig. 1 Completed and planned NASA Langley Transonic Dynamics Tunnel wind-tunnel tests for the HiLDA and AEI programs.

tests included the demonstration of Gust Load Alleviation (GLA), an enabling technology for a SensorCraft vehicle that will allow it to have reduced structural weight thereby increasing endurance, range, and payload capacity.

The HiLDA and AEI wind-tunnel investigations were conducted in the NASA Langley Transonic Dynamics Tunnel (TDT). The completed tests are depicted in figure 1 along with two planned AEI tests of the Boeing joined-wing ${ }^{2,3}$ SensorCraft vehicle concept where a full span model will be considered. The first two wind-tunnel tests were conducted as part of the HiLDA program. These included a short test of several candidate sensors for measuring gust flow angle. The HiLDA wing was tested September 2004 with gust load alleviation being demonstrated on a cantilevered mount using the model's five active control surfaces. ${ }^{4-6}$

The HiLDA wing was retested in October 2006, where it was mated to a new, multi-degree-of-freedom mount. This mount allowed the half-span model to translate vertically and pitch at the wing root, allowing better simulation of the full span vehicle's rigid-body modes. Following some modifications to the mount system, the wing was tested on the mount again in the summer of 2007. Figure 2 depicts the wing and mount system in the final configuration used in Test 598. The upstream flow angle sensor or gust sniffer is also shown in the image. During this test, GLA control systems were demonstrated in the presence of gusts generated by the TDT Airstream Oscillating System with peak wing bending loads being reduced by up to 60 percent, and BFF suppression control laws were demonstrated with flutter dynamic pressure being increased up to 50 percent.

The large size of the flying wing model along with the rigid body degrees-of-freedom afforded by the new mount system, created many unique challenges to successfully and safely meet the AEI test objectives. A remotely actuated snubbing system that returned the

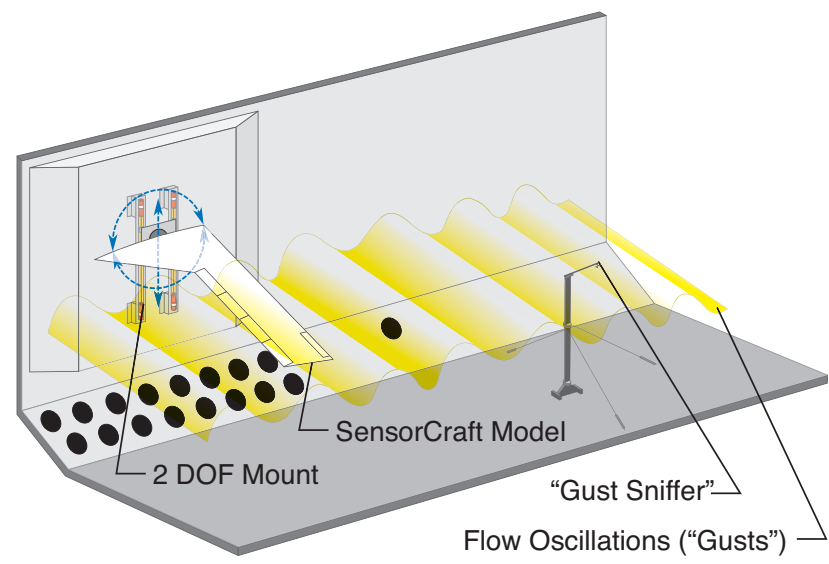

Fig. 2 Illustration of AEI apparatus installed in Transonic Dynamics Tunnel during Test 598.

model to a fixed angle-of-attack was included in the mount design. Determining how to effectively use this system was critical to the success of the test. Two digital control systems were used, one to implement the flap servo control loops and another to implement the trim, GLA, and BFF suppression control loops. The digital control systems included a safety monitoring (WatchDog) system for automatically triggering the snubbing system. Along with these systems, a variety of procedures had to be developed including those for model launch and recovery.

The purpose of this paper is to provide an overview of the AEI flying-wing wind-tunnel tests from an operational point of view with the focus on systems, procedures, and lessons learned. The paper includes descriptions of the hardware including the wind tunnel, the wing model, the mount system, and other supporting systems developed for this program. The software developed for the digital control systems will be described including the control law architectures and the WatchDog system. The main part of the paper will conclude with a description of the windtunnel testing procedures that were used. Finally, an appendix provides some additional analysis and testing details not covered in the main part of the paper. Throughout the paper, wind-tunnel data will be shown where applicable or necessary with an emphasis on the most recently completed test, Test 598 .

For the purpose of clarity, a brief overview of the model launch schemes, the flight control architectures, and the WatchDog system is warranted. Two model launch schemes were used, the TakeOff and the Release launch schemes developed for use by Northrop Grumman and Lockheed Martin, respectively. Throughout this paper, the TakeOff launch scheme will be associated with the NG control architecture where trim and suppression controllers are combined into a single control loop. The Release launch scheme will be associated with the LM control architecture where 


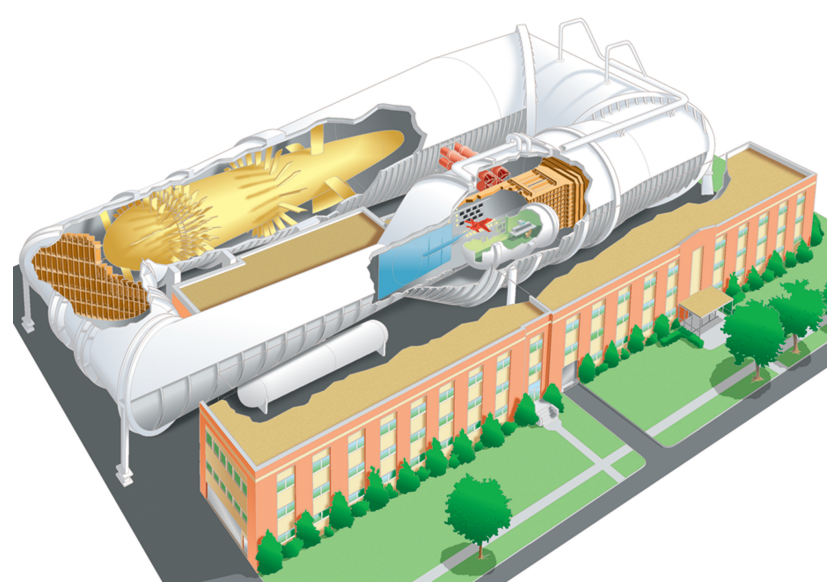

Fig. 3 NASA Langley Transonic Dynamics Tunnel.

trim and suppression controllers are in separate control loops. In addition, a separate set of WatchDog monitored parameters and associated limits are used with each launch scheme. These topics will be discussed separately in the paper.

\section{Transonic Dynamics Tunnel}

The Langley Transonic Dynamics Tunnel (TDT), depicted in figure 3 , is a unique national facility dedicated to identifying, understanding, and solving relevant aeroelastic and aeroservoelastic problems. The TDT is a closed-circuit, continuous-flow, variablepressure, wind tunnel with a 16 -foot square test section with cropped corners. ${ }^{7}$ The tunnel uses either air or a heavy gas as the test medium and can operate at total pressures from near vacuum to atmospheric. It has a Mach number range from near zero to 1.2 and is capable of maximum Reynolds numbers of about 3 million per foot in air and 10 million per foot in heavy gas. Until 1996, the TDT used dichlorodifluoromethane, R12 , as the heavy gas test medium; since then the TDT has used 1,1,1,2 tetrafluoroethane, R-134a, ${ }^{8,9}$ an environmentally acceptable alternative to $\mathrm{R}-12$.

The TDT is specially configured for flutter testing, with excellent model visibility from the control room and a rapid tunnel shutdown capability for model safety. Testing in heavy gas has important advantages over testing in air: improved model to full-scale similitude (which results in heavier, easier to build models with lower elastic mode frequencies), higher Reynolds numbers, and reduced tunnel power requirements.

Due to the need to perform GLA testing as part of the AEI program, the TDT Airstream Oscillation System (AOS) was used frequently. The key features of the AOS system are shown in the illustration in figure 4. These features include biplane arrangements of vanes on either side of the entrance to the test section. Each pair of vanes is driven by a separate hydraulic motor and a flywheel to hold constant vane frequency.

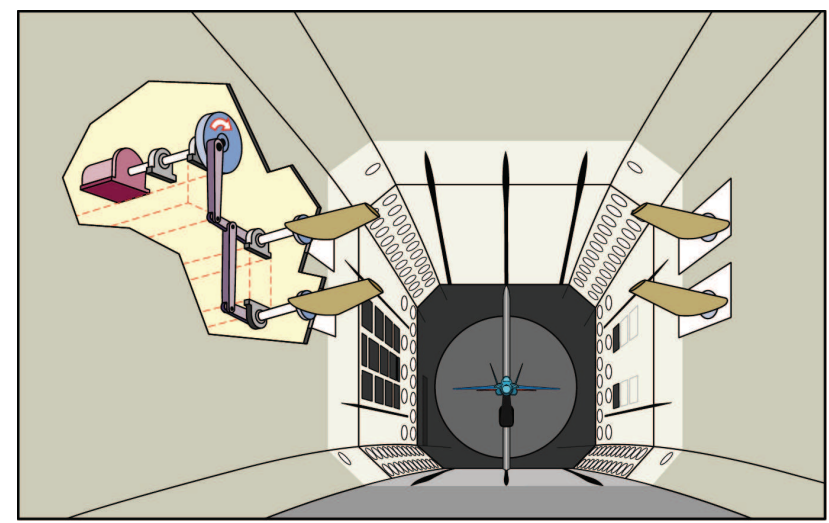

Fig. 4 Illustration of the TDT Air Stream Oscillating System (AOS).

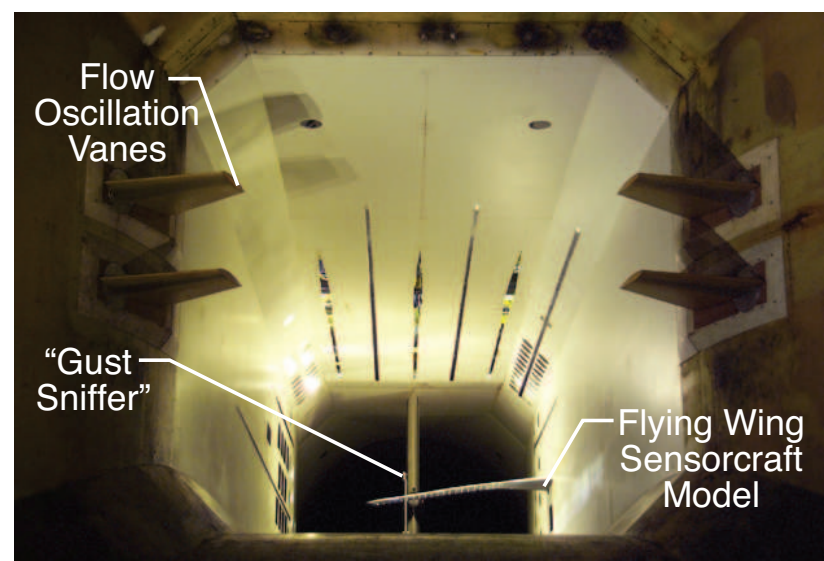

Fig. 5 Photo of the HiLDA model taken from Transonic Dynamics Tunnel settling chamber.

While the two pairs of vanes can be run out of phase, this was not done in the AEI test. Vane frequency was adjusted from the TDT control room manually or by using a LabView system. The amplitude of the vanes is manually adjustable from $0^{\circ}$ to $12^{\circ}$ peak-to-peak. For most of Test 598 , the $12^{\circ}$ peak-to-peak setting was used providing approximately a $\pm 1^{\circ}$ down wash in the vicinity of the model. For the last week of Test 598, the vane amplitude was reduced to $4^{\circ}$ peak-to-peak.

\section{Wing and Mount System}

The wing and mount system were designed and fabricated by NextGen Aeronautics in Torrance, California. NextGen Aeronautics was a subcontractor to the Northrop Grumman Corporation for the initial development of the wing for Test 579, and later, for the wing modifications and mount system design and fabrication for Test 593. NextGen Aeronautics was a subcontractor to the Lockheed Martin Company for the wing and mount modifications that preceded Test 598. This section of the paper will provide a description of the wing and mount system along with a discussion of the modifications that took place over the life of the program. A more detailed description of the 


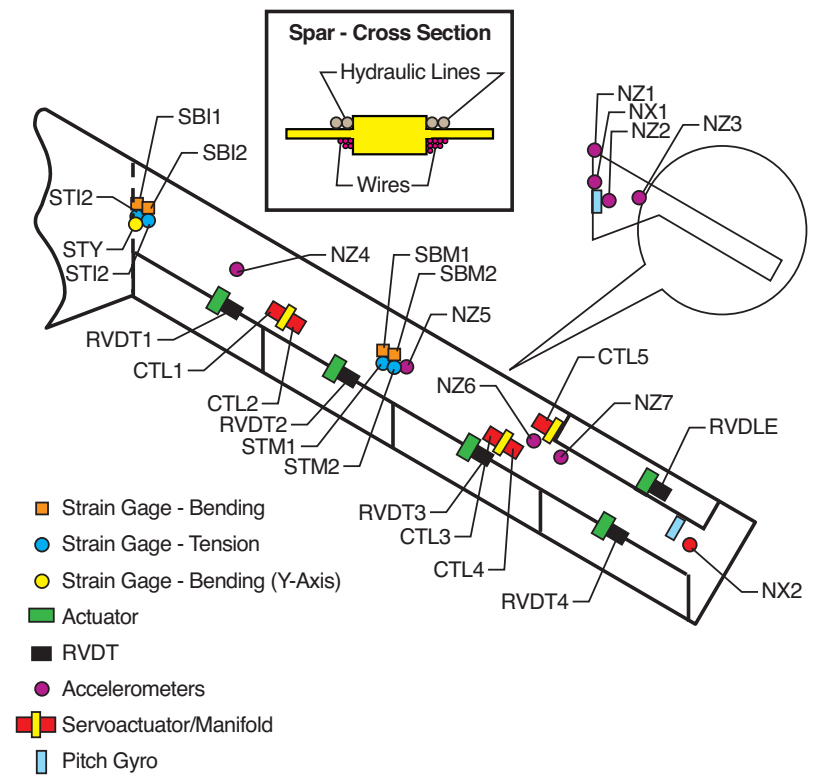

Fig. 8 Wing Instrumentation used for the AEI TDT tests (593 and 598). String potentiometers used for measuring pitch angle $(\Theta)$, vertical position $(\mathrm{PZ})$, vertical rate $(\mathrm{VZ})$, and moving mass position are not shown.

HiLDA wing can be found in references 4 and 5, and details associated with the wing and mount system can be found in references 10 and 11 .

The wing and mount system configuration used in Test 593 is shown in figure 6 , and the configuration used in Test 598 is shown in figure 7. These figures should be referred to when reading the sections that follow.

\section{Wing}

The wing is a $12 \%$-length scale, semispan model of a SensorCraft design concept originally designed for use in the HiLDA program. The outboard part of the wing is a spar-pod design where the scaled stiffnesses (EI and GJ distributions) are designed into the flanged aluminum spar, and the aerodynamic shape is provided by discrete fairings, or pods, mounted to the spar. The original set of pods was made from glass-filled nylon-12 (Duraform GF) manufactured using a stereolithography system. The inboard wing was intended to act as a rigid member and consisted of aluminum spars and internal ribs with fiberglass upper and lower skins. The closeout ribs for the inboard wing were stainless steel to provide the structural attachments for the 5-DOF balance at the root and for the outboard, flexible spar at the wing break. Lead weights could be attached to the spar to simulate fuel weight at the take off configuration.

The wing has four evenly spaced trailing edge control surfaces and one leading edge control surface on the outboard, flexible portion of the wing. The five control surfaces were driven by vane-type hydraulic actuators with position measured by Rotary Variable Differential Transducers (RVDTs). Two separate hydraulic systems were included in the model so that the trailing edge flaps could be operated at 1,000 psi, while the more heavily loaded leading edge flap could be operated at up to 2,000 psi. Other instrumentation included strain gages, accelerometers, a pitch-rate gyro, and a gust vane placed in front of the model to allow lead gust information to be fed into the controller. Figure 5 shows a photo of the HiLDA wing installed in the TDT from the settling chamber.

In preparation for the first AEI test, TDT Test 593, several modifications were made to the HiLDA wing. As rigid body degrees-of-freedom were being introduced as a result of the new model mount system, overall mass and center of gravity became important considerations. To adjust the model CG, the LE caps of the inboard part of the wing were modified so that six blocks of lead could be installed to provide up to 30 lbs of forward ballast. In addition, a moving mass system was included in the rigid root section that provided remote adjustment of the model CG. The device consisted of a compact stepper motor coupled to a ball screw actuator driving a $32 \mathrm{lb}$ ballast weight. The ballast assembly was restrained by two linear slides with a string potentiometer for position measurement. To simplify the model's hydraulic requirements, a larger leading edge actuator was built for this test so that it could operate at the same hydraulic pressure as the trailing edge flaps.

Modifications to the HiLDA wing's instrumentation suite included changes to the accelerometer locations to better measure the free-free mode shapes and the addition of a pitch rate gyro near the wing root. The instrumentation layout used in both AEI tests is shown in figure 8. Not shown in this figure are leading edge stagnation point sensor arrays developed by Tao Systems that are described in reference 12. Finally, the pods and control surfaces were redesigned to simplify installation and removal, and they were fabricated using a different material (Watershed 11120) to avoid concerns over moisture absorption. Unfortunately, the 11120 material has a low glass transition temperature, and the pods warped due to elevated temperatures in transit to the TDT.

Changes to the wing in preparation for TDT Test 598 were limited largely to maintenance items; however, two important modifications were made. First, the pod material was changed back to Duraform to avoid heat related warping. Duraform GF was used for the new pods, and Duraform AF was used for the new control surfaces. To minimize moisture absorption, all pod surfaces were sealed using primer. The second modification was deemed necessary when, during in- 


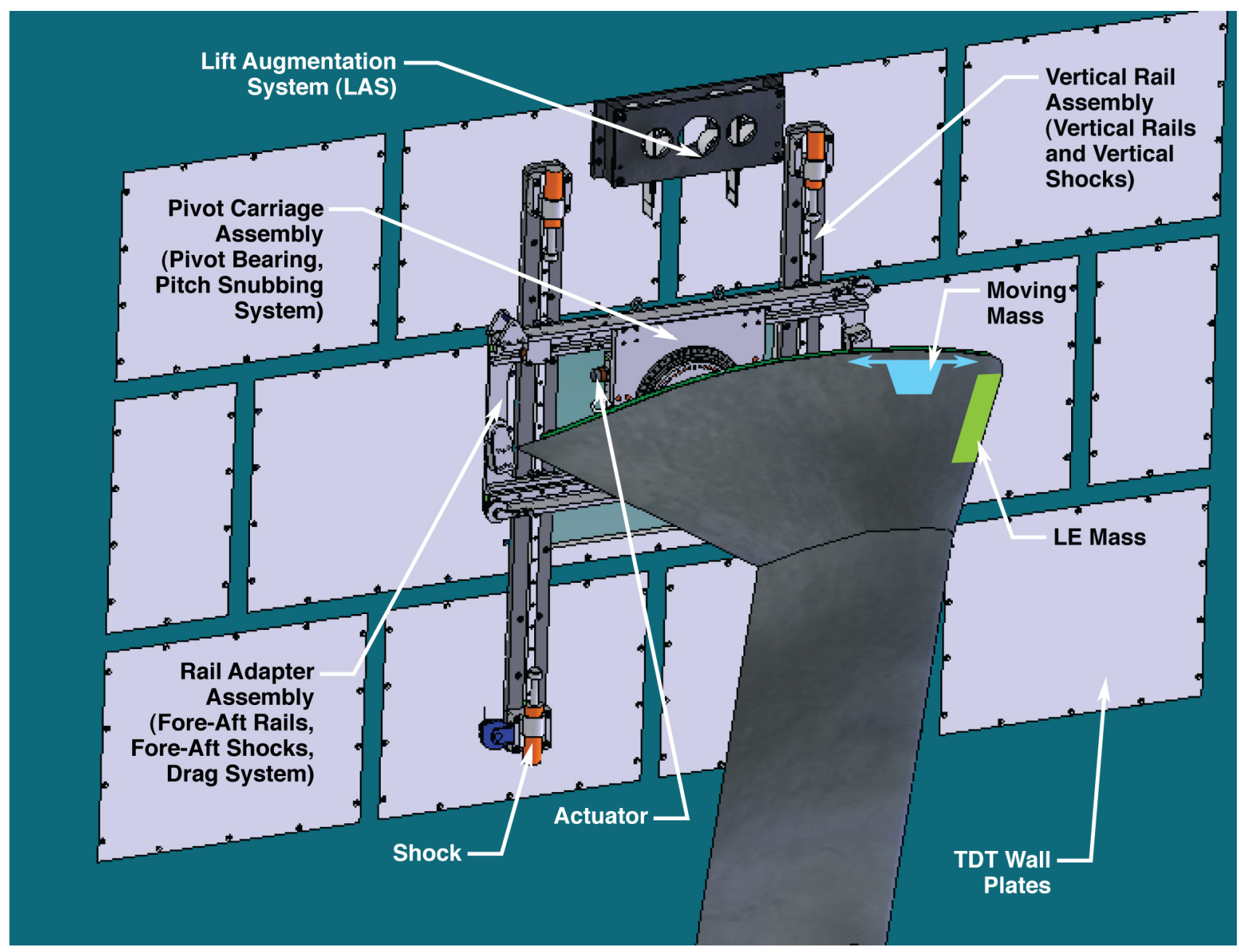

a) Mount system components.

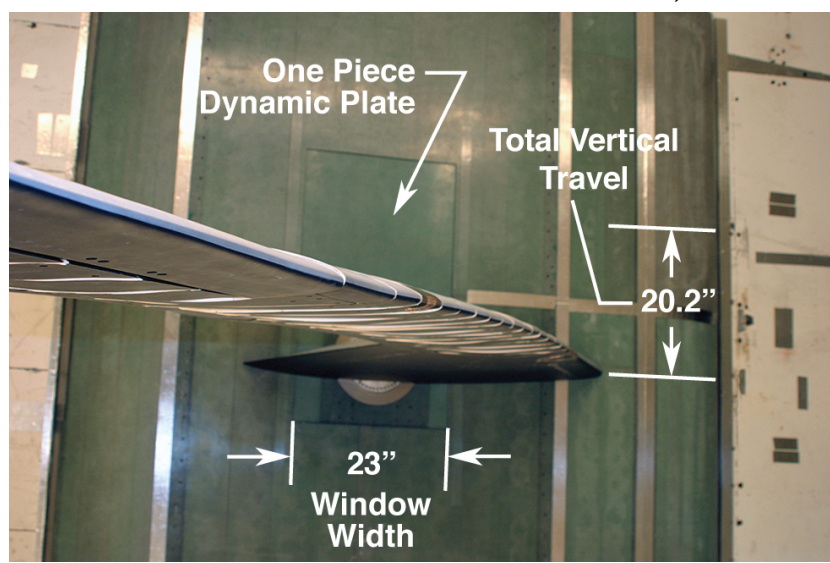

b) Original fairing assembly with large dynamic plate. Total vertical travel includes 14.2 inches of free travel plus the 3 inch strokes of the upper and lower shocks.

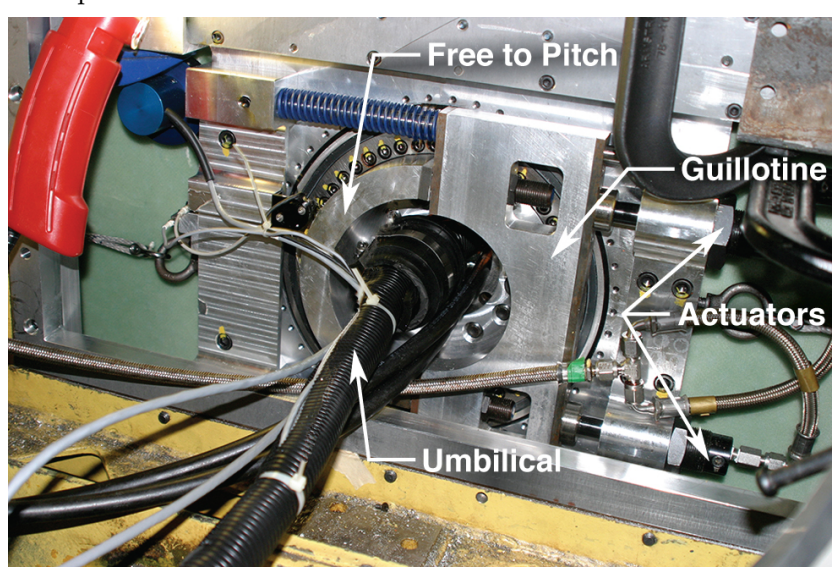

c) Back side of pivot carriage showing snubbing mechanism and umbilical.

Fig. 6 Original, 3 degree-of-freedom mount configuration used in Test 593.

spection, it was determined that the inboard wing had been overloaded during Test 593. Wind-tunnel data from this event will be shown later in the paper. As shown in 7 , a steel strap was added to the upper and lower surfaces of the inboard wing to strengthen the center spar by providing an additional load path between the two stainless steel ribs.

Appendix A describes the performance and challenges associated with using and maintaining the wing flap actuators during Test 598. 


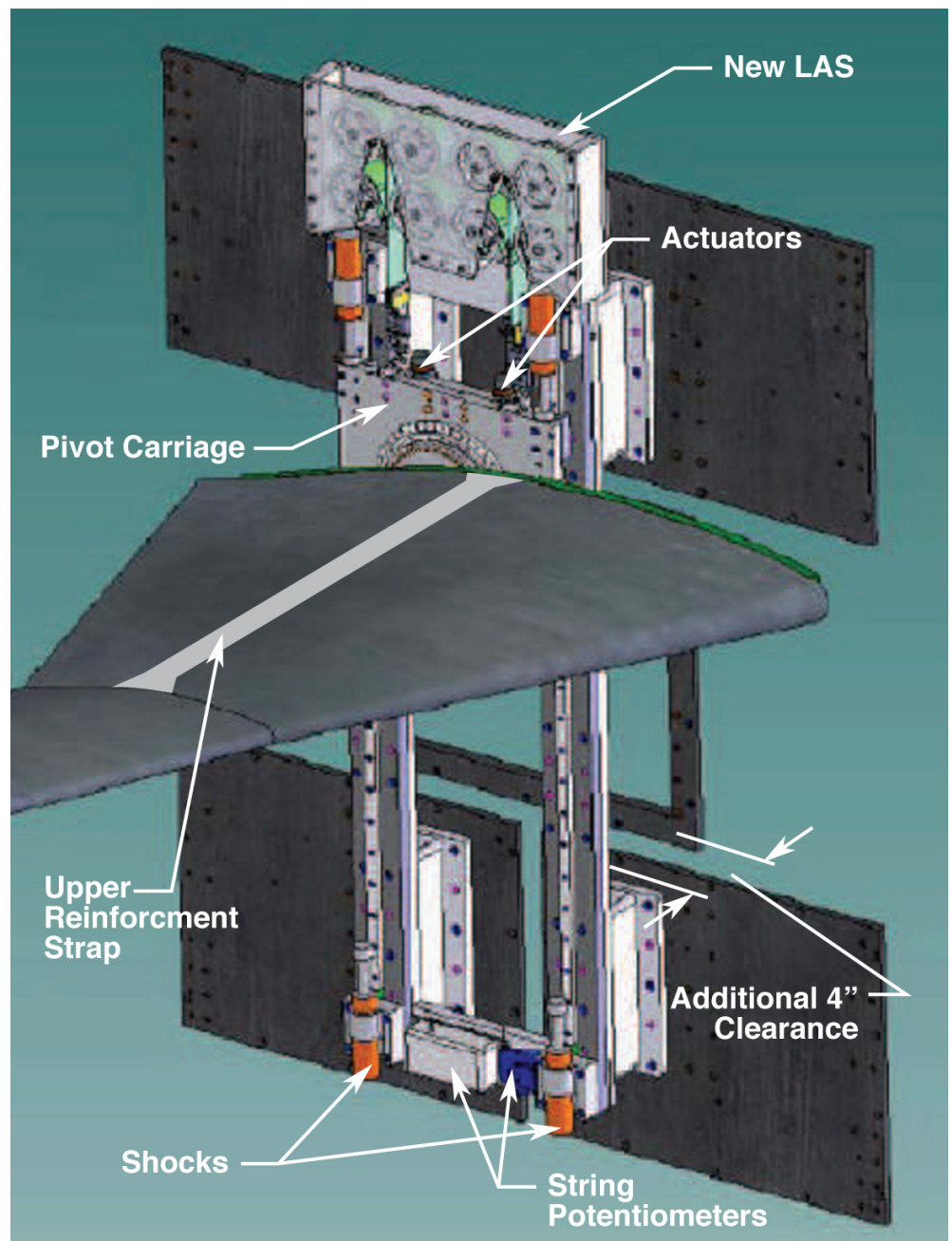

a) Revised mount system.

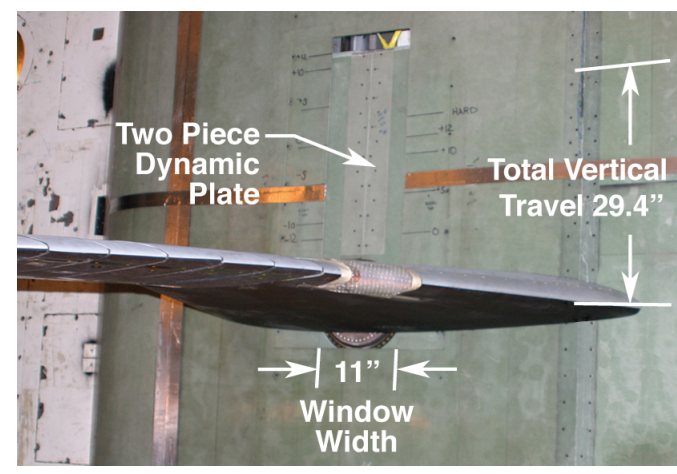

b) Revised fairing assembly with smaller window and dynamic plate. Total vertical travel includes 23.4 inches of free travel plus the 3 inch strokes of the upper and lower shocks.

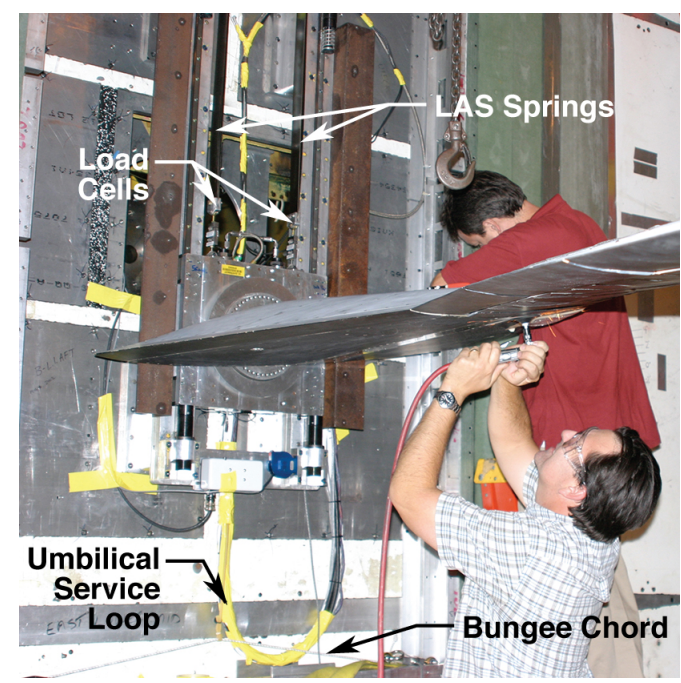

c) Installed mount system showing umbilical service loop.

Fig. 7 Revised, 2 degree-of-freedom mount configuration used in Test 598.

\section{Mount System}

The sidewall multi-degree-of-freedom mount system evolved considerably over the course of the two TDT tests in which it was used. Initially for Test 593, the mount was configured to provide 3 degrees-of-freedom, pitch, plunge, and fore-aft translation. This configuration is pictured in figure 6 . Based on the operational experience gained in Test 593, several significant changes were made to the mount system in preparation for Test 598. These changes included the removal of the fore-aft DOF and a complete redesign of the lift augmentation system. The revised system is shown in figure 7 . The key elements of the mount system along with the various design changes will be described next.

The pivot carriage assembly was the heart of the mount system. It consisted of the pivot bearing and the hydraulic pitch snubbing mechanism. The snubber consisted of two linear hydraulic actuators that moved a sliding plate (guillotine) that clamped against alternate ends of the half-circle, free-to-pitch structure that attaches to the wing. The back side of the pivot carriage assembly showing the pitch snub components and the hydraulic/instrumentation umbilical exiting the model through the center of the bearing assembly is shown in figure 6 . A string potentiometer was used to measure model pitch angle during both tests, and another string potentiometer was added prior to Test 598 to provide a direct measurement of the guillotine position. For the unsnubbed condition, the total rotation was controlled by adjusting the retraction distance of the guillotine by adjusting the hydraulic cylinder mount position. For the snubbed condition, replaceable pads on the free-to-move structure allowed control of the clamped angle pitch angle. Test 593 had a range of motion of $-12^{\circ}$ to $+16^{\circ}$ with a clamped angle of $+2^{\circ}$, and test 598 had a $-6^{\circ}$ to $+8^{\circ}$ range of motion with a clamped angle of $+1^{\circ}$. The range of motion was restricted to reduce the risk of damaging the model. Appendix B describes experiments used to assess and improve the performance of the snubbing system. 
The rail adaptor and vertical rail assemblies provided the translational DOFs via THK $20 \mathrm{~mm}$ width rails and guide blocks. Mil Spec bungee cords, cables, and pulleys were used to restrain for fore-aft DOF, and 40 " stroke string potentiometers were used to measure the fore-aft and vertical position of the pivot carriage assembly. To minimize impact loads, the vertical rail assembly included dashpot shock absorbers at the top and bottom. During Test 593, it was determined that the fore-aft DOF was heavily damped and as a result, no significant fore-aft motion was noted during testing. In preparation for Test 598, the assembly that provided the fore-aft DOF, the rail adaptor, was removed. The pivot carriage assembly was rotated $90^{\circ}$ and attached directly to the vertical rails as shown in figure 7 .

A fairing assembly enclosed the mount system. The fairing consisted of fixed exterior fiberglass panels with a cutout or window that allowed for a range of travel of the wing attachment. The window was covered with a dynamic plate that attached directly to and moved with the pivot carriage assembly. The fairing assembly used in Test 593 is shown in figure 6. The elimination of the fore-aft DOF for Test 598 allowed the width of both the window and dynamic plate to be reduced from 23" to 11 " as shown in figure 7 . As a result, the fixed fairing could be better supported, eliminating contacts between the fixed fairing and the wing root and the fixed fairing and dynamic plate. A new smaller, two-piece dynamic plate design was used in Test 598. The allowed the dynamic plate to be removed for access mount system components without the need for removing the wing.

A lift augmentation system (LAS) was required to compensate for the mass of the carriage system and excess inboard wing weight. The first iteration of the LAS consisted of 8 constant force springs that provided approximately $40 \mathrm{lbs}$ of force each for a total lift augmentation of $320 \mathrm{lbs}$. The springs could be attached to the rail adaptor in groups of two via a lanyard and cable assembly. This first system suffered from high friction associated with the spring tapes twisting and rubbing against the spool frame assembly. The redesigned system used in Test 598 again used 8 constant force springs, but due to the weight savings associated with the elimination of the fore-aft DOF and the removal of the rail adaptor assembly, springs providing $20 \mathrm{lbs}$ of force each could be used. These springs attached to the pivot carriage assembly via pinned ball joint with load cells in series so that LAS force could be monitored during the test. Other design improvements included spring spool assemblies with an improved set of bearings and a LAS frame design that minimized potential spring tape contact points.

The original vertical rail assembly consisted of two independent components that bolted directly to the
TDT wall plates as shown in figure 6 . As a result of irregularities in the wind-tunnel wall, shimming was necessary to avoid binding the plunge DOF. Also, the hydraulic/instrumentation umbilical had to exit straight out of the assembly as shown in figure 6 . Because there was limited space between the pivot carriage assembly and the wind-tunnel wall, free vertical travel was restricted to \pm 7.1 inches of the designed \pm 12 inches to avoid cutting the umbilical on the opening in the wind-tunnel sidewall. The free travel does not include the 3 inch strokes of the upper and lower shocks, so total vertical travel is 6 inches greater than the free travel. The redesigned mount shown in figure 7 included a new standoff support frame that simplified mount installation and provided an additional 4 inches of clearance from the wind-tunnel wall. These changes allowed the hydraulic/instrumentation umbilical to form a service loop inside the fairing, under the pivot carriage assembly, as shown in figure 7. For Test $598 \pm 11.7$ inches of vertical travel was achieved in this configuration.

Appendix $\mathrm{C}$ describes the experimental methods used to estimate the friction in the vertical rails and to monitor the health of the LAS.

\section{Test Configurations}

In Test 598, the model was tested in two configurations: heavy and light. The heavy configuration had 5 of 6 inboard leading edge masses, all wing fuel weights, and all 8 LAS springs installed. The light configuration had no wing fuel masses, 2 of 6 inboard leading edge masses, and 4 LAS springs installed. The total free flying weight of the heavy and light models was $442 \mathrm{lb}$ and $356 \mathrm{lb}$, respectively.

The boundary conditions and hence, the dynamic characteristics of the wing were altered considerably by the state of the mount system. For instance, when the snubbing system was engaged and the pivot carriage was held on the lower stop via gravity, the wing was essentially cantilevered at the root. The pitch DOF could be freed by releasing the snubber, and the plunge DOF was only free when the model was in trimmed flight. Thus, the mount system provided four distinct boundary conditions that had to be considered. The various boundary conditions, mount states, and first mode frequency are shown table 1 . For the heavy configuration, the frequencies were determined by a ground vibration test performed in the TDT model preparation area, and for the light configuration, frequencies were determined via NASTRAN analysis. ${ }^{11}$

\section{Signal Routing, Processing, and Control}

A high level schematic of the signal routing arrangement used in Tests 593 and 598 is shown in figure 9. 
Table 1 Model Boundary Condition and the Frequency of the 1st Bending Mode.

\begin{tabular}{cccccc}
\hline \hline \multicolumn{2}{c}{ Bndry Cond } & \multicolumn{2}{c}{ Mount State } & \multicolumn{2}{c}{ 1st Mode, Hz } \\
Pitch & Plunge & Pitch & Plunge & Heavy & Light \\
\hline Fixed & Fixed & Snub & On Stop & 1.9 & 2.1 \\
Fixed & Free & Snub & Trim & 2.0 & 2.3 \\
Free & Fixed & Trim & On Stop & 3.0 & 3.3 \\
Free & Free & Trim & Trim & 3.5 & 4.1 \\
\hline \hline
\end{tabular}

All input and output signals were routed from their source to the TDT control room via a built-in wiring system. Most instrumentation was routed to a Pacific Instruments series 6000 chassis that provided instrument power ( 5 or $10 \mathrm{VDC}$ ), signal amplification, and anti-alias filtering. The RVDTs and Rate Gyros required \pm 15 VDC power so a custom power supply was fabricated with the signals subsequently routed through the Pacific Instruments chassis for amplification and anti-alias filtering. The anti-aliasing filters were set to $400 \mathrm{~Hz}$ for the RVDTs as they were routed only to a digital control system running at a 1,000 $\mathrm{Hz}$ frame rate (dSpace1), and all other signals were filtered at $100 \mathrm{~Hz}$ to be compatible with the other digital control system running at a $200 \mathrm{~Hz}$ frame rate (dSpace2). Servovalve signals were routed to a Moog voltage-to-current converter and back to the model as shown in the figure. Model signals were "Teed" and routed to a strip chart for monitoring and to the TDT Data Acquisition System (DAS) for recording. The TDT DAS was set to record data at $500 \mathrm{~Hz}$ with its own anti-aliasing filters set to $200 \mathrm{~Hz}$.

The snubber control system, dSpace1 and dSpace2 internal block diagrams, and the external signals communicating between these systems are depicted in figure 10. All signals external to the dSpace blocks are analog, with dSpace input signals being converted from volts to engineering units prior to processing and output signals being converted from engineering units back to volts. For signals intended to depict discrete system states, programming logic was used to decode the meaning of the signal.

The hydraulic actuators in the snubbing system were operated by a solenoid valve that was controlled using the snubber control system. The heart of the snubber control system was a latching circuit that can be tripped by a manual chicken switch or a Snub! command signal from dSpace1. The status of the latching circuit (snubbed or unsnubbed) was communicated back to the dSpace systems by the SnubStat signal shown in figure 10. A detailed description of the snubber control system and associated hydraulic components is described in a separate section, below.

The trim, GLA, and/or BFF suppression control laws were implemented on dSpace2. As shown in figure 10, dSpace2 had two internal control blocks and a set of externally generated flap commands that could be summed and output as analog flap command signals to dSpace1. Throughout most of Test 598, only the upper dSpace2 control block was used with two versions being implemented, one developed by Northrop Grumman and the other developed by Lockheed Martin. This upper control block contained GUI interface and some programming logic for controlling or initiating certain events like resetting the system or initiating a launch. Details of the NG and LM flight control architectures including their associated programming logic will be described later. The FlightMode state is communicated to the WatchDog system as shown.

The servo-control loops, the WatchDog system, and the Weight on Wheels (WoW) switch estimator were implemented on dSpace1. The servo-loops were independent PID control loops equipped with output saturation blocks to prevent overdriving the actuators. The WoW switch was a hysteresis block intended to provide debounce or noise tolerance. The WatchDog system monitored the model signals and when a fault was detected, would issue a Snub! command and transfer flap control to the emergency control laws via the switch shown in 10 .

Details of the dSpace hardware and software development environment will be described next, followed by a description of the hydraulics and snubber control system.

\section{DCS Hardware and Development Environment}

Each dSPACE DCS consists of a rack containing a host computer, a target system, a rack mounted keyboard and monitor, BNC patch panels for IO, and an uninterruptible power source. The heart of the DCS is the target system that includes a dSPACE DS1006 control processor board utilizing a $2.6 \mathrm{GHz}$ AMD Opteron processor connected to three dSPACE DS2002 multi-channel A/D boards and one dSPACE DS2103 multi-channel D/A converter board. The A/D boards each have 32 channels utilizing 16 bit quantization with an input range of 10 Volts. The D/A board contains 32 channels of 14 quantization bits designed for 10 Volts and a settling time of $10 \mu \mathrm{sec}$.

The controller software is developed within the MatLab Simulink environment, then compiled and downloaded to the target processor via the dSPACE and MatLab Real-Time Interface. An integral component of the dSPACE tools is the ControlDesk application. ControlDesk provides the user interface to the target processor for the development and implementation of the visual control and indication medium. The target processor is the embedded controller and the host provides the user interface, visual display, and controls all 


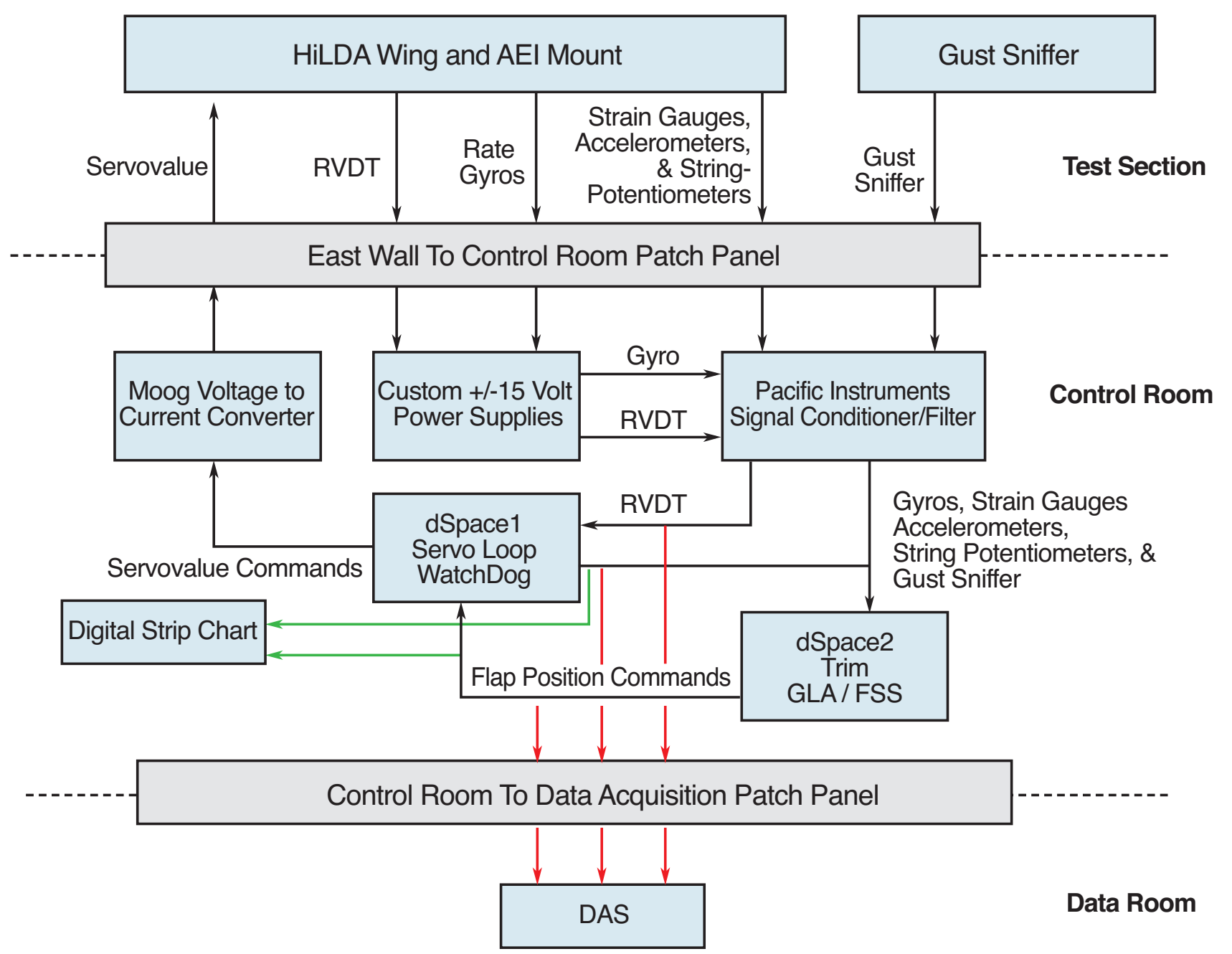

Fig. 9 Signal routing used in Test 593 and 598.

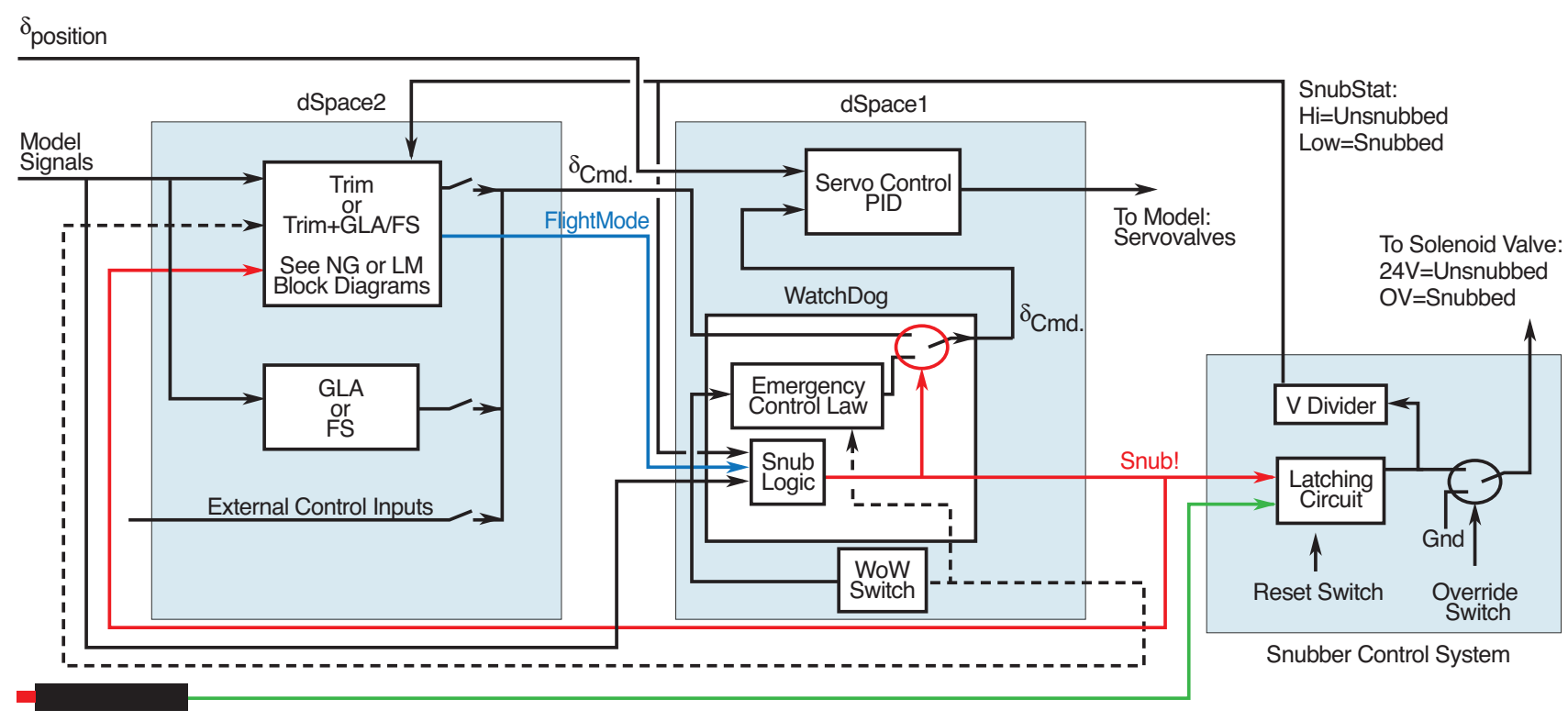

Manual Chicken Switch

Fig. 10 dSpace and snubber control block diagram. 


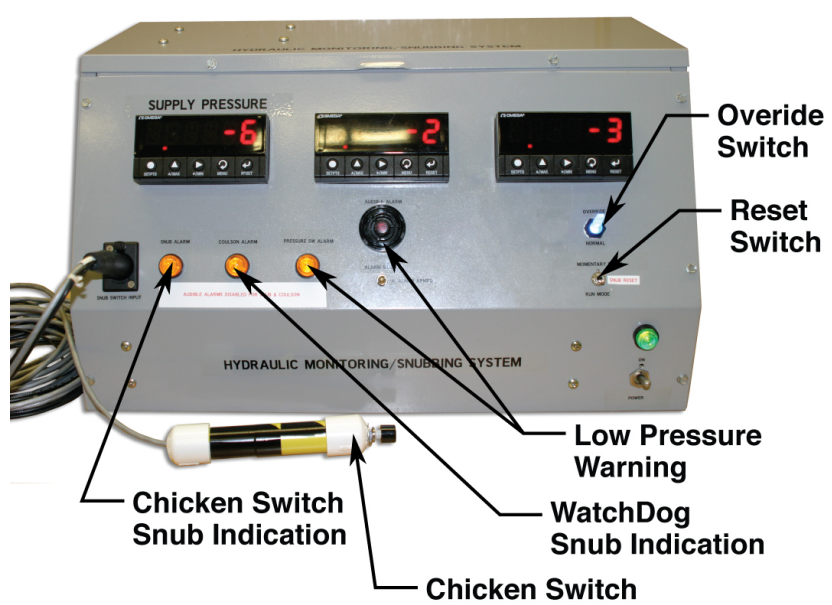

Fig. 11 Snub control chassis containing the snub control system with manual Snub! switch and hydraulic pressure displays.

communications between the processors.

\section{Hydraulics and Snubber Control System}

Hydraulic control of the pitch snub mechanism was accomplished using a custom snub control system housed in a chassis located in the TDT control room and a hydraulic manifold assembly located in the TDT plenum near the wind-tunnel model and mount. Hydraulic fluid, at 2,000 psi, was delivered to the hydraulic manifold assembly from the TDT 30 GPM pump. The manifold assembly consisted of an adjustable pressure switch, a Parker Hannifin solenoid valve, and two regulators for supplying up to two lower pressures to the wind-tunnel model. Hydraulic pressure transducers were included to monitor the supply/snub pressure as well as the two regulated pressures. The solenoid valve was normally open and required $24 \mathrm{VDC}$ power to remove pressure from the snubbing system thereby releasing the model.

The snub control chassis served two purposes, monitoring of the hydraulic systems and enclosing the snub control system. The chassis housed three hydraulic pressure displays showing supply/snub pressure and up to two lower, regulated model pressures. An amber light and an audible alarm were wired to the pressure switch to provide warning of reduced hydraulic pressure. The snub control system consisted of two mechanically latching relays that were used to send $24 \mathrm{VDC}$ to the hydraulic solenoid valve. The relays had their contacts wired in series so that either relay could cut the 24 VDC power to the hydraulic solenoid and independently snub the model. One relay was switched directly by the normally open hand-held chicken switch, and the second relay was switched by a voltage signal from an external source.

The snub control chassis and a handheld chicken switch are shown in figure 11. Two amber colored lights on the front of the snub control box indicated which source initiated the Snub! command, chicken switch or external source (WatchDog system). Resetting of the relays and lights was accomplished with a momentary toggle switch (reset switch). There was an independent toggle (override) switch to hold a snub condition. This switch was used to keep the model in a snubbed condition independent of the status of the relays allowing systems to be reset with out inadvertently cycling the snub system.

\section{WatchDog System}

Due to the high risk associated with aeroelastic wind-tunnel testing, a variety of manual and automated safety systems have been used in the TDT. The manually operated tunnel bypass valves are generally the first line of defense for flutter testing as they can rapidly reduce test section dynamic pressure and Mach number. Depending on the type of model and mount system employed, model stabilization or arrestment mechanisms have also been considered. Previously employed model stabilization devices have included decoupler pylons that change model dynamics to a more benign configuration and model arrestment devices including pneumatic snubber cables for cable mounted models. Manual engagement of these devices has at times been supplemented by automated systems. Such systems have previously been employed only for non flying models with the tunnel bypass valves and/or decoupler devices being triggered based on threshold exceedences. ${ }^{13}$

The range of rigid body motion and the potential for high speed impact afforded by the new mount system made the AEI flying wing tests among the riskier tests conducted in the TDT. The snubber mechanism was intended to reduce risk to the model and facility, and could be triggered manually. However, human reaction times for 'simple' tasks like the sheep dash game in reference 14 are only around 0.22 seconds, and more advanced tasks, like dodging a baseball, requires a full 0.4 seconds. ${ }^{15,16}$ In the tunnel testing environment, the test engineer must in essence perform system ID in real-time to determine whether a behavior is a benign oscillation or a potentially fatal divergence, mix in a little hope, and the reaction time can be significant. This point is driven home by the worst overload case from Test 593 where the automated system was not used. Figure 12 shows time histories for vertical position, pitch angle, and inboard bending moment acquired during a failed model launch attempt. For this data point, the peak bending load significantly exceeded the design load of 15,000 in-lbs preceding the manual Snub! command. Clearly, a robust automated system was necessary, and the WatchDog system was developed for this purpose. 


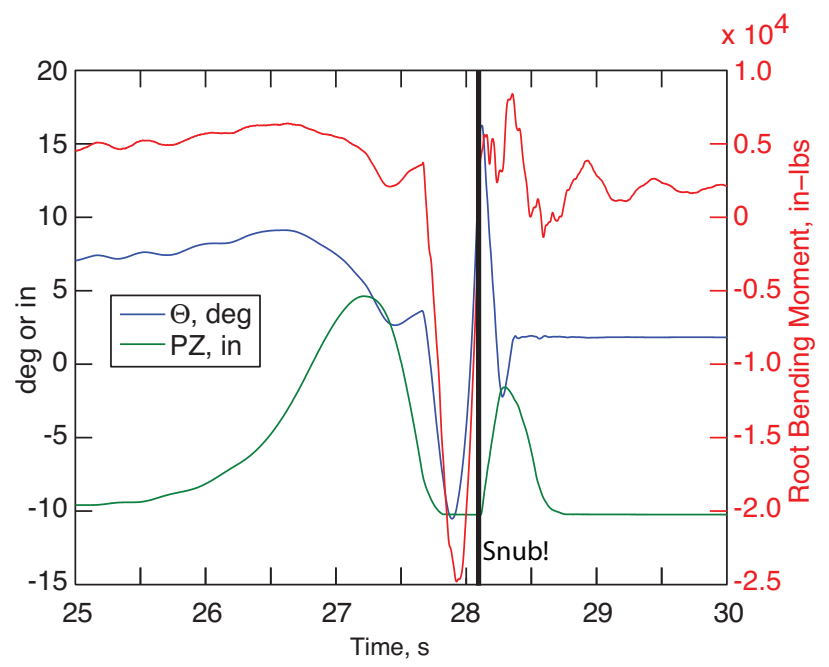

Fig. 12 Worst case bending overload condition from Test 593, Point 1833. The bending moment is measured from strain gauge SBI1 shown in figure 8 corrected for outboard wing weight.

The WatchDog system was developed to keep the model and mount system from exceeding structural safety limits by monitoring signals from the wing and mount system. Difficulty in updating limits and a large number of false positives limited WatchDog use in Test 593. By Test 598, the need for an improved WatchDog system was well established and the deficiencies of the previous implementation were corrected. The system was also expanded to satisfying the differing needs of both Northrop Grumman and Lockheed Martin.

The WatchDog was implemented on dSpace1 as shown in figure 10. The key features of the WatchDog system are the emergency control law and the snub logic. The snub logic monitors the model signals and issues a Snub! command when a fault is detected. Issuing the Snub! command engages the pitch snubber and switches model flap control from dSpace2 to the emergency control law as shown in the figure. The subsections that follow will describe the emergency controller, the snub logic, and some enhancements and unique features that were developed for use by Northrop Grumman and Lockheed Martin for Test 598 .

\section{Emergency Controller}

When the model is snubbed, the aerodynamic lift becomes a function only of the dynamic pressure and control surface position. In the snubbed condition, the flaps can be used as lift only devices, as the pitching moment generated is counteracted by the snubbing mechanism. As a result, a simple emergency controller could be developed to arrest the vertical motion and safely land the model after the Snub! command had been issued.

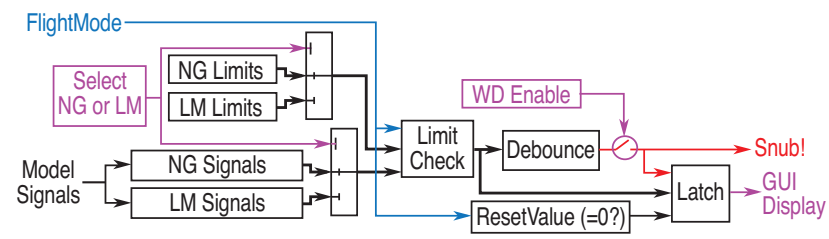

Fig. 13 WatchDog system snub logic block diagram.

The emergency controller flew the model in the snubbed condition using vertical position error and vertical velocity feedback. The controller gains were divided by the measured dynamic pressure to produce a controller that worked over the dynamic pressure range of interest. The controller also had a flap bias term $\left(\delta_{o}\right)$ consisting of the expected control surface positions that would provide total wing lift equal to net wing weight, actual wing and pivot carriage weight less LAS force. These bias values were also a function of dynamic pressure, and were initially determined by simulation and then updated as part of the testing process. This testing process will be described later in the paper.

\section{WatchDog Snub Logic}

A block diagram of the WatchDog snub logic is shown in figure 13. The system's primary function was to monitor the 32 model signals and issue the Snub! command when parameter limits had been exceeded. The WatchDog could be enabled or disabled by the user from the dSpace1 GUI. While rarely disabled during Test 598, the feature was needed to facilitate testing under unique circumstances.

From the dSpace1 GUI, the operator can select either the NG or LM limits and signals to be used with the NG or LM control law architectures, respectively. Both NG and LM signal blocks included the basic set of 32 model signals along with some calculated values called combined parameters. The NG and LM limit sets each included a discrete set of upper and lower parameter limits for each FlightMode. The FlightMode was used to select between the sets of limits, so that a different set could be used for reset, takeoff, flight, or GLA testing. The exact definition of the FlightMode parameter was depended on which flight control architecture was being used, NG or LM. In ether case, when the FlightMode associated with model launch and climb out was used, the lower model position limits needed to be ignored until a the model cleared a certain height (PZ value). NG accomplished this by having a separate FlightMode and WatchDog limit set for Take off and climb out. LM did not use a separate FlightMode and WatchDog limit set, but instead had some coded logic built into the LM Signals block that ignored the lower position parameters until a certain $\mathrm{PZ}$ value had been reached. A more detailed descrip- 
tion of these processes will be provided in the flight control schemes section of the paper.

The selected signals and FlightMode dependent limits were compared in the Limit Check block. Detected faults were passed to the Debounce block where 3 consecutive frames of any particular signal fault were required to issue the WatchDog Snub! command. This prevented a single frame noise event from issuing a false alarm. A latch was used to quickly diagnose the cause of WatchDog commanded Snub! events. The parameter that caused the trip would be held and displayed to the user via the GUI on dSpace1. The WatchDog latch was reset by setting the FlightMode mode to zero.

Preliminary modeling and review of past tests allowed for initial values of the WatchDog limits to be set. As the wind-tunnel test progressed, some limits were expanded based on operational experience. For example, as lower frequency gusts were tested, vertical velocity and pitch rate became large exceeding initial WatchDog limits, but since model response remained stable and bounded, the WatchDog limits were expanded to permit testing. During testing, the limit values could be modified directly in the real time processor memory from the DSpace1 user interface. These modifications were then recorded back into MatLab script files for future use.

\section{NG - Combined Parameters}

Based on the WatchDog system deficiencies identified during Test 593, Northrop Grumman proposed that combined parameters be considered in addition to nominal set of 32 model signals. For example, if the model had negative vertical position (too low) and positive vertical velocity (moving up), that would be acceptable. Alternatively, the combination of negative position and negative velocity would be cause for concern. Thus, multiplying vertical position (PZ) and vertical velocity(VZ) produced a parameter that was acceptable when negative and given a safe upper limit and monitored by the WatchDog $(\infty<\mathrm{PZ} \times \mathrm{VZ}<$ limit $)$. An additional parameter of $\mathrm{PZ} \times \mathrm{VZ}^{2} \times \operatorname{sign}(\mathrm{VZ})$ was also used and was a good indicator of dangerous conditions. These combined parameters increased model safety and provided relatively few false alarms. The NG combined parameters were implemented within the NG Signal block in figure 13. The NG combined parameter limits were set initially by simulation and then modified throughout the test, as deemed necessary by the test team.

\section{LM - Combined Parameters}

A different set of combined parameters was developed by Lockheed Martin based on an estimate of the vertical location up and down where the emergency controller can bring the model to a stop once

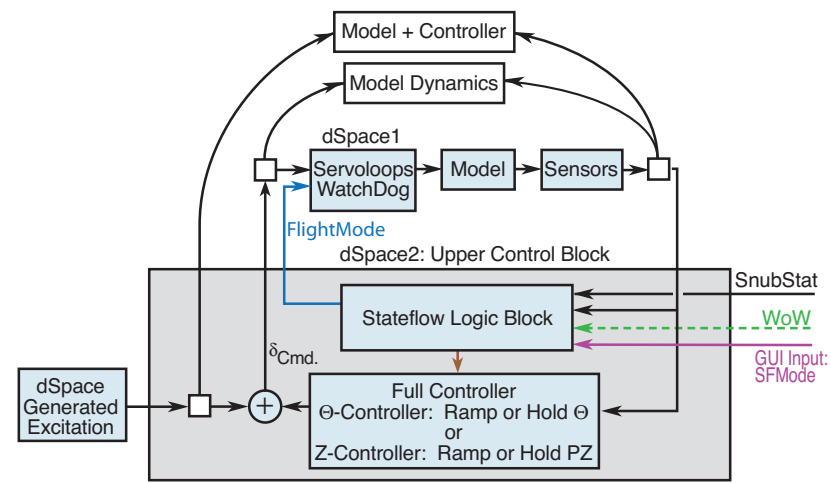

Fig. 14 Control law and FlightMode logic developed by Northrop Grumman.

the snubber had been engaged. These two combined parameters were generated by a feedforward estimator in series with a neural network implemented within the LM Signal block in figure 13. Appendix D provides a detailed description of the simulation model, neural network, and Test 593 data analysis used to develop and validate the LM combined parameters.

\section{Flight Control Schemes}

Two schemes for achieving trimmed flight were developed and demonstrated. They were the TakeOff and the Release schemes developed by Northrop Grumman and Lockheed Martin, respectively, with the assistance of NASA Langley Research Center. The TakeOff scheme simulates a take-off roll, acceleration, rotation, and lift-off. Alternatively, the Release scheme kept the model snubbed until flight speed was achieved in the tunnel, then it was unsnubbed and lifted off. This section will describe each launch scheme and its associated control law architecture. Example wind-tunnel data will be provided where appropriate.

\section{Takeoff Launch Scheme}

The TakeOff launch scheme approximates an aircraft takeoff process beginning with a high speed ground roll, followed by rotation, lift off, climb, and finally, trimmed flight. The control law architecture associated with the TakeOff launch scheme is shown in figure 14. As shown in the figure, the TakeOff launch scheme makes use of the MathWorks Stateflow package. Stateflow extends Simulink with a design environment for developing state machines and flow charts. The NG implementation of Stateflow, allows most TakeOff launch scheme actions to be event driven. The Stateflow Logic Block is controlled by the Stateflow Mode (SFMode) parameter via the dSpace2 GUI as indicated

The TakeOff launch scheme requires two separate controllers. A $\Theta$-controller is used during the pitchfree condition when the model is on the lower vertical 


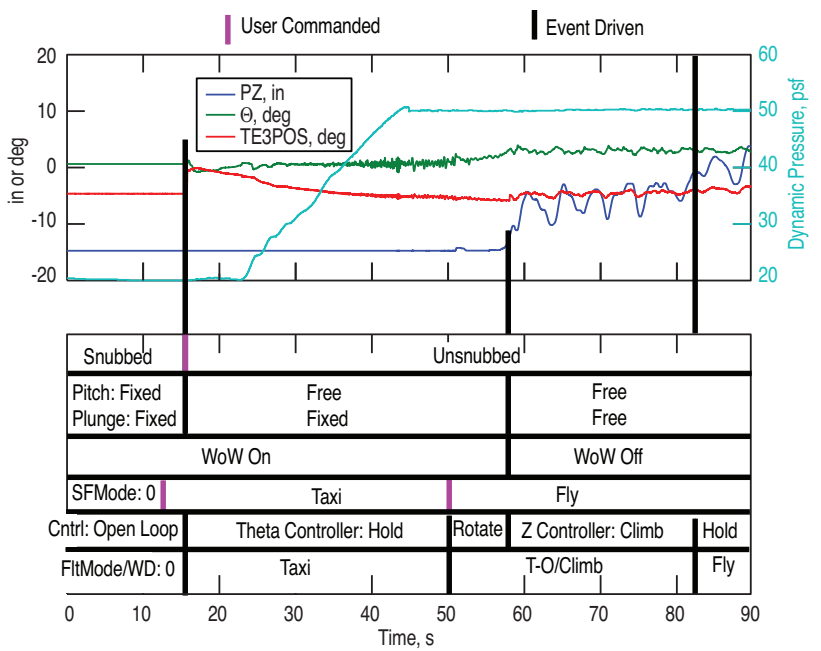

Fig. 15 Data acquired while using TakeOff launch scheme to achieve trimmed flight. Test 598, Points 1274, 1275, and 1276 .

stop, and a Z-controller is used when the model takes off and transitions to the free-free boundary condition. The control laws implemented in the figure were developed using the LQG method and incorporated GLA and trim control into a single controller. This allowed studies to be performed that directly traded short period performance with GLA performance. The design of these controllers and their initialization methods are discussed in more detail in reference 17.

Data acquired during implementation of the TakeOff launch scheme are shown in figure 15. Here, time histories of PZ, $\Theta$, flap 3 position, and dynamic pressure are plotted in the upper part of the figure, and the timing of boundary condition changes, Stateflow modes, and other system states are identified in the lower portion of the figure. User and event driven actions are identified. This figure should be consulted when reading the following TakeOff scheme steps listed below:

- $\mathrm{T}=0$ s: Start with model snubbed, dynamic pressure set to $20 \mathrm{psf}$, and SFMode set to 0. Stateflow sets FlightMode to 0 telling the WatchDog to use the reset limits.

- $T=13 \mathrm{~s}:$ Operator sets SFMode to Taxi. Controller is ready and waiting to detect the unsnubbing of the model via the SnubStat signal from the snubber control system.

- $\mathrm{T}=15 \mathrm{~s}$ : Operator unsnubs the model using the reset switch on snubber control system chassis. Stateflow senses the unsnub condition via the SnubStat signal and initiates the $\Theta$-controller. It also changes FlightMode to Taxi telling the
WatchDog system to use the Taxi limits

- $\mathrm{T}=24$ to $45 \mathrm{~s}:$ Dynamic pressure is increased to the launch value of $50 \mathrm{psf}$

- T=50s: Operator sets SFMode to Fly. Stateflow then starts the $\Theta$ set point ramp and changes FlightMode to T-O/Climb telling the WatchDog system to use the T-O/Climb limits.

- $\mathrm{T}=58 \mathrm{~s}$ : The model lifts off the lower stop and passes through the WoW switch causing Stateflow to transition from the $\Theta$-controller to the Z-controller. PZ set point for the Z-controller is ramped up toward tunnel centerline. Also, as WoW switch is cleared, the model boundary conditions transition to free-free.

- $T=83 \mathrm{~s}:$ Stateflow senses that PZ has reached a value of -1 inch and changes the $\mathrm{PZ}$ set point to the tunnel centerline value of zero. Stateflow also changes FlightMode to Fly telling the WatchDog system to use the Fly limits.

- $T_{¿} 90 \mathrm{~s}:$ Dynamic pressure increased, as necessary, to the desired test condition. Operator can set SFMode to Test. Stateflow then changes FlightMode to Test which tells the WatchDog system to use the Test limits. When testing is complete, snubber chicken switch is used to manually engage the snubbing system and land the model using the emergency control law.

This method was shown to be successful and led a better understanding of the model in early testing. However, the large dynamic pressure changes that were required for each launch made it very time consuming. In addition, the pitch-free boundary condition is not very stable and is significantly more difficult to control than the free-free boundary condition. As a result, engineering effort had to be used to develop stable $\Theta$ controllers. Also, the transition from the $\Theta$ controller to the Z-controller must have a small enough transient not to overly perturb the model. Thus, the Zcontroller controller bandwidth and performance was being driven by the need to mitigate the takeoff transition. While this challenge is understood and manageable in conventional flight control architectures, it presents particular challenges when investigating large state-space controllers.

\section{Release Launch Scheme}

For the release launch scheme, the control surfaces were prepositioned for flight prior to releasing the 


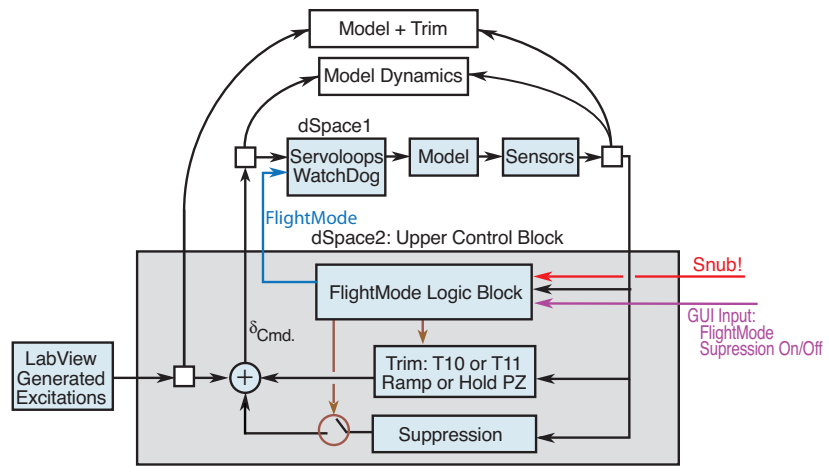

Fig. 16 Trim and suppression control loops along with FlightMode logic developed by Lockheed Martin.

pitch snub mechanism so that when the snubber was released the model flies off the bottom stop. The model transitions from the stable Fixed-Fixed boundary condition to the stable free-free conditions without dwelling at the unstable Free-Fixed condition. This quick transition does not allow the unstable pitchfree configuration to build up any response amplitude. Therefore, there was no need to control the pitch-free configuration using a $\Theta$-controller.

The control architecture used with the release method was a two-loop system as shown in figure 16 . The inner loop contained the trim controller and was responsible for flying the model, and the outer loop contained the suppression controller and was responsible for reducing the dynamic response. The suppression controller could be switched on and off with little or no effect on the average control surface trim position. As a result, switching between controllers caused little trim/elevation change and was done frequently throughout the test to acquire GLA data with as many controllers as possible without having to repeat the launch procedure.

The trim controller consisted of vertical position PID gains a plus pitch rate gain and a static (bias) term. The proportional and integral terms were ignored until the model was unsnubbed. The output of the trim controller was a single command that was sent to all four trailing edge flap surfaces. The trim controller gains were initially established from analysis, and a single set of trim controller gains were identified that were applicable to both the heavy and light model. The bias term and the dynamic trim gains could be adjusted from the dSpace2 GUI. Two versions of the trim controller were used during Test 598, T10 and T11. Trim controller T11 was better suited to TDT operations with the AOS system operating.

The suppression controllers were developed utilizing the system identification and LQR/LQG techniques described in reference 18. System identification data was acquired around the inner loop as indicated by the thin lines in figure 16 providing the model+trim system dynamics. These system identification data were then used with the LQR/LQG methods to build the suppression controller. Therefore, the suppression controllers were aware of and expected the trim controller to be part of the system. This subject is covered in more detail in reference 19 .

As with the TakeOff launch scheme, the WatchDog limits associated with the Release launch scheme had to be set to ignore the lower position limits during the launch and climb out phase of flight. For the TakeOff launch scheme, the logic for ignoring lower vertical limits was contained entirely within the Stateflow logic block, and a separate set of WatchDog limits was selected for this phase of flight. For the Release launch scheme, a separate FlightMode for launch and climb out was not used. Instead, logic was built into the LM Signal block shown in figure 13 that ignored certain parameters until PZ had reached a value of -5 in. Another difference between the two launch schemes is that in the TakeOff launch scheme the operator sets the SFMode parameter via the GUI, but FlightMode is event driven via the Stateflow logic block. Here, the operator sets the FlightMode via the GUI when using the Release launch scheme.

For the Release launch scheme, FlightMode 0 was a reset mode, FlightMode 1 was a trim control only mode, and FlightMode 2 allowed the use of the suppression loop. Each FlightMode had a different set of WatchDog limits. FlightMode 1 was used for launch and climb out, so parameters that would snub the model when it was on the lower stop were ignored until PZ reached a value of -5 in. To protect the model during takeoff, in FlightMode 1 the WatchDog $\Theta$ lower limit was set to $0^{\circ}$ to minimize the possibility of a pitch over and subsequent hard landing event.

Data acquired during implementation of the Release launch scheme are shown in figure 17. Here, time histories of PZ, $\Theta$, flap 3 position, and tunnel dynamic pressure are plotted in the upper part of the figure, and the timing of boundary condition changes, FlightMode changes, and other system states are identified in the lower portion of the figure. User and event driven actions are identified. This figure should be consulted when studying the following TakeOff scheme steps listed below:

- T=0s: The model is snubbed. Tunnel dynamic pressure is set to the launch value of 50 or 60 psf. FlightMode is set to zero by the operator causing the control surfaces to be pre-positioned by the static part of the trim controller $\left(\delta_{o}\right)$. This also puts the WatchDog in reset mode, 0 . The reset mode gets the latching logic associated with the lower position limits in WatchDog limit set 1 ready for launch. 


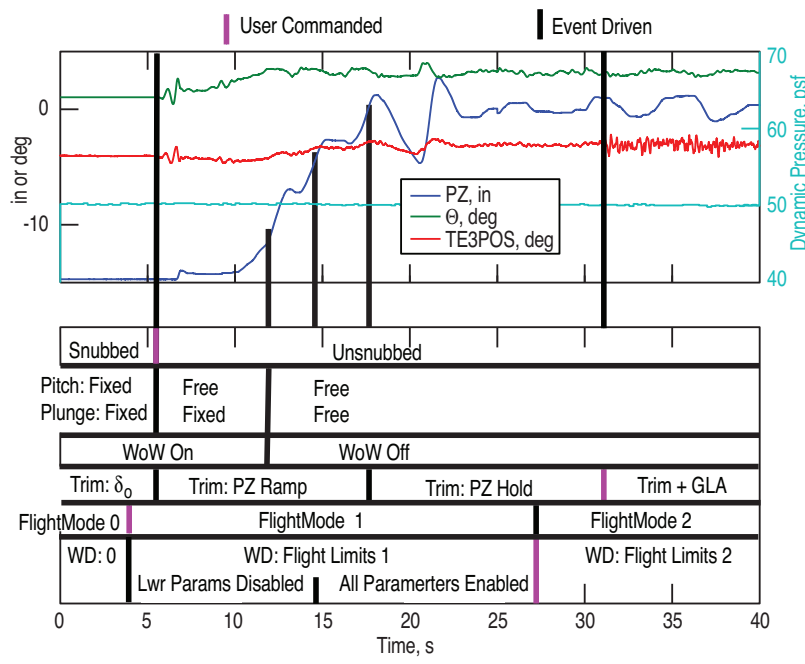

Fig. 17 Data acquired while using Release launch scheme to achieve trimmed flight. Test 598, Point 2384.

- $\mathrm{T}=5.5 \mathrm{~s}:$ Operator unsnubs the model using reset switch on snubber control system chassis. The FlightMode logic block within the LM flight control architecture senses the unsnubbed condition via the Snub! command signal and initiates the dynamic part of the trim controller. The PZ setpoint for the trim controller begins ramping to tunnel centerline. The model starts to rotate but does not immediately lift off. This is an unstable condition and the model starts to oscillate in pitch.

- $\mathrm{T}=7 \mathrm{~s}$ : The model lifts off the bottom stop and is supported on the damper. The integral part of the trim controller continues to increase the control surface deflection and $\Theta$.

- $T=12 \mathrm{~s}:$ The model clears the WoW switch indicating that it is off the dampers and has transitioned to the free-free boundary condition. This event does not trigger any action within the Release scheme and associated LM control architecture.

- T14s: The vertical position passes through -5 inches and the WatchDog begins monitoring all signals including the lower vertical limits.

- $\mathrm{T}=17 \mathrm{~s}:$ The model vertical position passes through tunnel centerline $(\mathrm{PZ}=0)$, and the $\mathrm{PZ}$ set point for the trim controller is set to zero by the FlightMode logic block in the LM flight

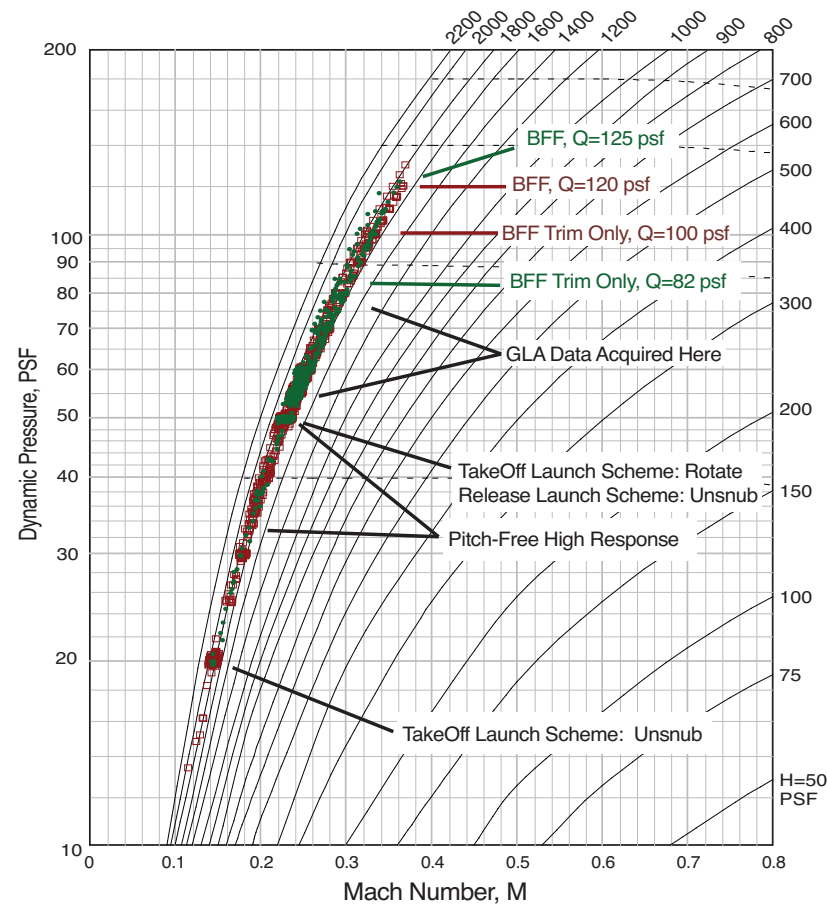

Fig. 18 Portion of the TDT heavy gas operating envelope showing data acquired during Test 598 where red represents the heavy weight configuration and green represents the light weight configuration.

control architecture.

- $\mathrm{T}=27 \mathrm{~s}: \quad$ FlightMode is manually changed to FlightMode 2 which allows the use of the suppression control law but does not close the suppression loop.

- $\mathrm{T}=31 \mathrm{~s}: \mathrm{A}$ suppression controller is engaged by the operator via the dSpace 2 GUI. The higher frequency control surface activity is associated with the suppression loop being closed.

The Release launch scheme proved to be easy, effective, and insensitive to dynamic pressure and model configuration.

\section{Testing Procedures}

With the exception of several air checkout runs, all Test 598 data was acquired in heavy gas with a tunnel total pressure between 1,670 and 1,880 psf. This maps to a fairly tight band of Mach number and dynamic pressure combinations as shown in figure 18 where a portion of the TDT heavy gas operating envelope is shown along with the Test 598 data points. At any given tunnel total pressure, Mach number and dynamic pressure are controlled by varying the RPM of the TDT main drive motor. For the test procedure 
of Test 598, increasing RPM varied tunnel conditions along the plotted data points starting with the lower left. As Mach number is relatively insensitive to tunnel RPM in this region, dynamic pressure was used to identify all tunnel conditions.

As previously mentioned, the model and mount system had four testable boundary conditions. Data presented in table 1 showed that the first bending mode frequency changed significantly based on these conditions, and as a result, model flutter speeds varied with snub and flight status. Due to the possibility for high speed vertical impact, the riskiest configuration was with the model in a free-free, flying configuration. The safest configuration was with the pitch DOF snubbed and the model sitting on the lower stop. For both the heavy and light configurations, the relatively safe configurations were cleared for flutter and the functionality of the emergency controller verified prior to proceeding with free-free flight at a give dynamic pressure. The subsections that follow will describe the various test procedures in general order of increasing complexity

\section{Open-Loop Flutter Clearance}

The model/mount system could be tested open-loop when the pivot carriage was sitting on the lower mount with and without the pitch snub mechanism engaged. Flutter clearance testing of these configurations was performed in a manner typical of TDT flutter testing. Dynamic pressure was increased slowly while the model was monitored visually and its signals monitored via strip chart.

For the Fixed-Fixed case, flutter clearance was somewhat pro forma, as this configuration had the least modeling unknowns, the highest analytical flutter speeds. ${ }^{4}$ Also, it had previously been tested in this configuration (Test 579 and Test 593) up to a dynamic pressure of at least 80 psf. During Test 598, the free-free configuration was only cleared for flutter to a dynamic pressure of 60 psf. The high degree of confidence in the analysis and the concern that the model would not remain on the lower stop during this testing due to the fixed, positive, snub pitch angle precluded flutter clearance testing above 60 psf.

The other open-loop configuration that was tested for flutter was pitch-free with the model on the lower stop. This configuration required that the model be manually trimmed to keep pitch angle from getting too large causing the model to lift off the lower stop. This configuration was of interest because it was the model boundary condition state for the Taxi mode in the TakeOff launch scheme. The exact flutter onset dynamic pressure was somewhat ambiguous for this configuration as this flutter mechanism appeared to be a hump mode with a very shallow flutter crossing.
Experimentally, this was demonstrated by an inconsistent flutter dynamic pressure and a relatively benign flutter mechanism. This behavior occurred at dynamic pressures between 30 and 50 psf.

\section{Snubbed Flight Clearance and Emergency Controller Validation}

The next stop on the way toward achieving trimmed, free-free flight was to verify and tune the emergency controller. The purpose of the emergency controller was to gently return the model to the lower stop using gains and biases scheduled with dynamic pressure. The bias values had to be adjusted based on experimental data. An additional purpose of this testing was to simultaneously verify that the model was flutter free in the snubbed flying configuration up to the maximum expected dynamic pressure of interest.

The process for clearing the model for flutter was to fly the model in the snubbed configuration at tunnel center line $(\mathrm{PZ}=0)$ and incrementally increase dynamic pressure stopping approximately every 10 psf. Once aeroelastic stability had been established, controller validation data was acquired using the emergency controller to track a sawtooth position command between -10 inches and +10 inches with a ramp rate of \pm 1 in/sec. Data was acquired for 3 complete saw tooth cycles. The average control surface position needed to fly the model at each dynamic pressure was determined and used as the static component $\left(\delta_{o}\right)$ of the emergency controller.

In preparation for GLA testing this clearance/validation process was performed from the takeoff dynamic pressure of 50 psf to 70 psf, the maximum dynamic pressure where GLA data would be acquired. In preparation for BFF testing, the process was repeated for dynamic pressures above 70 psf to a maximum dynamic pressure of 130 psf. The testing process had to be repeated for the light model.

\section{Gust Load Alleviation Testing}

So far, this paper has described the apparatus, procedures, and preliminary testing that were necessary to achieve trimmed, free-free flight in a safe and predictable manner. Demonstrating that a control law reduced loads due to gusts required that data be acquired using different control laws all in the same gust environment. Here, the acquisition of the GLA data with the TDT AOS system operating will be discussed.

The biggest problem encountered with AOS testing was simply to get the model in a trimmed flying state with the AOS operating. Initial attempts failed when the model was first launched into a stable, trimmed flight condition prior to turning on the AOS. The AOS uses a large flywheel to hold constant vane frequency, and therefore, changes in frequency occur relatively slowly. As a result, when the AOS system 
was engaged, the model encountered a low frequency sinusoidal gust field with flow angles of approximately $\pm 1^{\circ}$ (at the initial AOS amplitude setting of $12^{\circ}$ peakto-peak). The vertical travel required for the wing to fly through this gust field exceeded the vertical travel available on the mount system, and the WatchDog system or test engineer would snub the model. The solution to this problem was to bring the AOS on-line prior to launching the model. An AOS frequency well above the rigid body modes and between the resonant frequencies of the flexible modes (1st in-plane and 2nd out-of-plane bending) was used, typically 6.5 or $9.5 \mathrm{~Hz}$. This technique allowed both the TakeOff and Release launch schemes to be successfully used.

An interesting aside regarding the AOS is that on several occasions launch sequences that had previously been successfully employed failed to work. In these instances, the model would fly to the top of its vertical travel and trip the WatchDog system. It was determined that the AOS vanes had been parked at a nonzero angle, and this flow angularity change was enough to cause the model to fly to its upper travel limit during launch attempts. Re-zeroing the AOS vanes solved the problem.

For the Release scheme, it was experimentally determined that trim controller T10 could only be used during model launch with the AOS off. Thus, the trim controller gains had to be adjusted slightly in order to successfully launch the model when the AOS was operating. Two versions of the Release scheme trim controller were ultimately used, the AOS and non-AOS versions or T11 and T10 trim controllers, respectively. The higher gains in T11 provided a snappier launch and better position tracking. Although T11 could be used to launch the model with and without the AOS operating, this was generally not done as T10 was the preferred baseline controller for the AOS off cases.

In the case of the TakeOff scheme, the same control laws could be used to launch with and without the AOS operational. Since trim and GLA were combined for the TakeOff scheme, the inherent disturbance rejection associated with GLA may have allowed these control laws to achieve this without any special AOS related design considerations.

At this point, the differences between the control law design methods associated with the TakeOff and Release schemes dictated how the testing for each was conducted. For the TakeOff scheme, the trim/GLA controllers were designed using state-space analytical models. LQG methods were employed where the weightings were varied to produce different controllers that provided various levels of GLA performance, and many such controllers were evaluated. The GLA evaluation procedure consisted of acquiring model response data for each control law subject to AOS dwells in 0.5 to $0.1 \mathrm{~Hz}$ frequency increments. Generally, this type of testing would start at a relatively high AOS frequency and proceed to lower frequencies until the WatchDog or test engineer snubbed the model. When the model was snubbed, the AOS operator would return to the system to $6.5 \mathrm{~Hz}$ to reduce the large amplitude wing bending oscillations associated with peak response frequencies and to prepare for another launch using a different control law. Figure 19 provides some example data where the AOS frequency was about 0.6 $\mathrm{Hz}$. Here, the vertical displacement is quite large approaching \pm 10 in. At $\mathrm{T}=4.9 \mathrm{~s}$, a WatchDog limit was exceeded and the model was snubbed and returned to the lower stop by the emergency controller.

When using the Release launch scheme and associated LM controller architecture, a system ID approach was used to generate the GLA controllers. The system ID data was acquired with uncorrelated random excitations sent simultaneously to each flap. These excitations were generated externally using a LabView system with the excitations added to the flap commands within dSpace 2 as shown in figure 16 . As discussed earlier, the system ID data needed to capture the model with the appropriate trim control loop engaged.

Acquisition of system ID data for use when the AOS was not engaged was relatively straight forward. However, a new procedure had to be developed to generate system ID data for generating GLA controllers for use with the AOS system engaged. Here, the external frequency command feature of AOS was used with the LabView system to sweep through the frequency range of interest. Typically, this was from an upper frequency of 9.5 to $11 \mathrm{~Hz}$ down to a frequency slightly above where the model was expected to exceed WatchDog limits then back to the upper frequency. The random excitations were simultaneously sent to the flaps while the AOS system was sweeping.

Suppression controllers generated using these data could be evaluated using the AOS dwells, described above, or the AOS sweep excitation without the random flap inputs included. Time traces acquired during an AOS sweep are shown in figure 20. Here, the AOS frequency is varied from 9.5 to 2.0 back to $9.5 \mathrm{~Hz}$ during a 100 second data record. Large bending and plunge displacement responses were obtained at the low AOS frequencies.

The lowest frequency that could be obtained using either the AOS dwell or sweep excitations was a function of dynamic pressure. For the heavy model and a dynamic pressure of $70 \mathrm{psf}$, the WatchDog system would generally trip between 3.0 and $2.5 \mathrm{~Hz}$, and at 60 psf it would typically trip between 1.7 and $2.5 \mathrm{~Hz}$. The actual lower limit was a function of the specific controller engaged at the time. Similar trends were noted

17 OF 24 


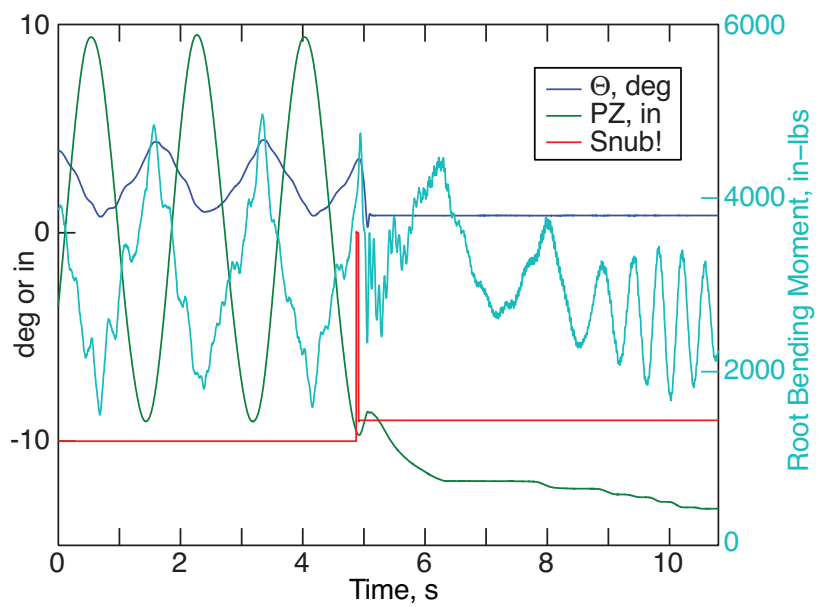

Fig. 19 AOS transitioning from 0.7 to $0.5 \mathrm{~Hz}$, WatchDog engaged Snub! command. Test 598, Point 4891. The bending moment is measured from strain gauge SBI1 shown in figure 8 corrected for outboard wing weight.

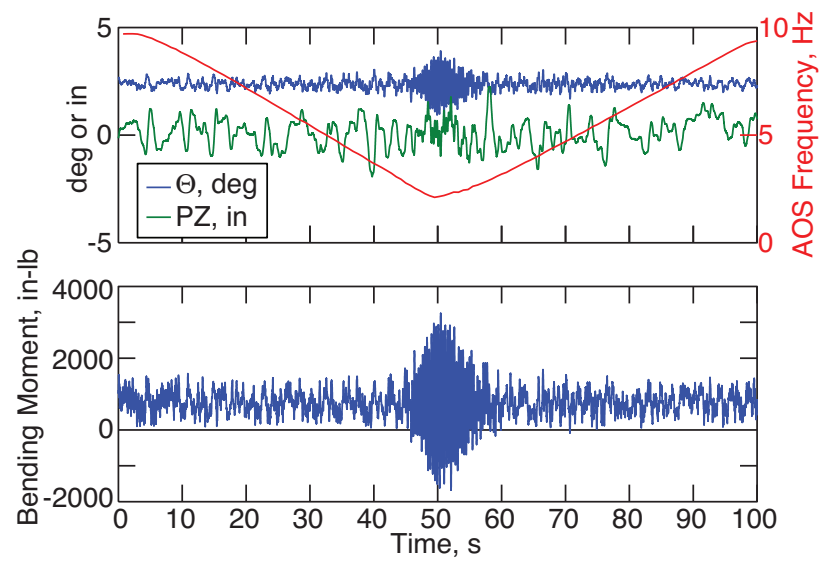

Fig. 20 Time traces of vertical position, pitch angle, and bending moment while AOS sweeping from 9.5 to 2.0 to $9.5 \mathrm{~Hz}$. Test 598, Point 3182. The bending moment is measured from strain gauge SBI1 shown in figure 8 corrected for outboard wing weight.

for the model in the light configuration; however, as the light model had a higher first bending mode frequency, the lower frequency limit at which data could be acquired was higher. For the final week of testing, the peak-to-peak amplitude of the AOS vanes was adjusted $12^{\circ}$ to $4^{\circ}$. Following this change, data could be acquired with AOS frequencies below $1.0 \mathrm{~Hz}$ for dynamic pressures of 60 psf as previously shown in figure 19 .

More details on the GLA control laws and the experimental results can be found in references 17 and 19 .

\section{Reduced Static Margin Testing}

The moving mass could be remotely adjusted from the TDT control room during wind-tunnel testing. For model launch and most subsequent testing, the nominal location of this mass was full forward for the heavy configuration and full aft for the light configuration. In the heavy configuration, the moving mass and model's CG could be moved aft to investigate reduced static margins. The procedure was to establish trimmed flight with the mass in the nominal (full forward) location and set the dynamic pressure to the desired value. Then the mass was moved aft incrementally until the model went unstable and was snubbed or the mass made it to the full aft position. Data was acquired periodically during this process.

\section{BFF Suppression Testing}

For flutter testing, the goal was to establish the experimental flutter onset dynamic pressure associated with a given control law. As with the flutter clearance testing, dynamic pressure was increased incrementally; however, since flutter was expected, the increments were reduced as dynamic pressure was increased into uncharted territory. For this testing, naturally occurring tunnel turbulence was generally deemed adequate to perturb the model, but control surface doublets were occasionally used to free stiction in the mount system. Ultimately, flutter onset was determined by the test engineer's assessment that the model was unstable or when the WatchDog limits had been exceeded. In either case, the model would be snubbed. Figure 21 shows data from one such BFF encounter where the WatchDog system engaged the snubber and the model was subsequently landed via the emergency controller. Note that $\Theta$ and PZ have the same frequency and are growing in amplitude.

Controllers associated with the TakeOff launch scheme were tested for flutter. However, BFF suppression was not a test objective of Northrop Grumman, and $\mathrm{BFF}$ testing was limited to experimentally determining the flutter onset dynamic pressure using the manner described above. System ID data was not acquired.

Controllers associated with the Release launch scheme were tested extensively for flutter in the heavy and light configurations. As the objective of this testing was to generate BFF suppression controllers that would increase flutter onset above the trim-controlleronly value, a boot strap method had to be employed. The first step was to establish the trim-controller-only (baseline) flutter onset dynamic pressure, acquiring system ID data incrementally as dynamic pressure was increased. This data was then used, off-line, to generate BFF suppression control laws. When testing resumed with the Trim+BFF-suppression controller engaged, system ID data would again be acquired as dynamic pressure was increased until a new flutter onset value was established. The system ID and 

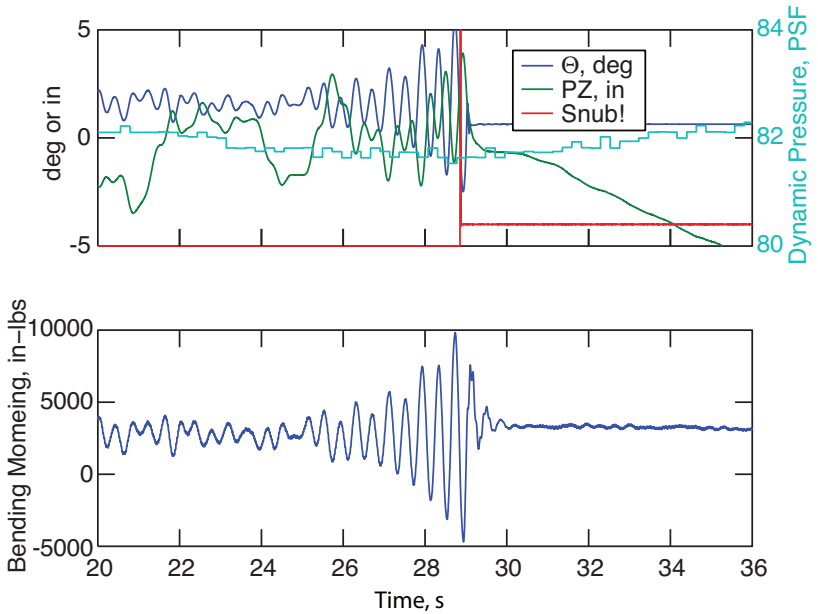

Fig. 21 Body freedom flutter time trace for trim only control, light model. WatchDog Snub! engagement shown along with vertical position ramp down. Test 598, Point 3525. The bending moment is measured from strain gauge SBI1 shown in figure 8 corrected for outboard wing weight.

control law design procedure was repeated until the maximum value of flutter onset dynamic pressure was established. More details on the BFF suppression control laws and a discussion of the experimental results can be found in references 11 and 19

\section{Concluding Remarks}

In the Fall of 2007, the Air Force Research Laboratory (AFRL), Northrop Grumman, Lockheed Martin, and NASA Langley Research Center successfully completed the third of a series of three wind-tunnel tests of an aeroelastically scaled wind-tunnel model of a flying wing SensorCraft vehicle concept. The first of these tests was conducted on a cantilevered, sidewall mount. The second and third tests (2006 and 2007) used a new, multi-degree-of-freedom mount. This mount allowed the semi-span model to translate vertically and rotate in pitch at the wing root, allowing better simulation of the full span vehicle's rigid-body modes. The large size of the flying wing model along with the rigid body degrees-of-freedom afforded by the new mount system, created many unique challenges to successfully and safely flying the model in the tunnel and meeting the AEI test objectives. This paper has provided an overview of the AEI flying-wing wind-tunnel tests from an operational point of view. It has focused on systems, procedures, and lessons learned that enabled the test to be successful in demonstrating Gust Load Alleviation (GLA) and Body Freedom Flutter (BFF) suppression. Descriptions of the hardware including the wind-tunnel, the wing model, the mount system, and other supporting systems developed for this program were provided.

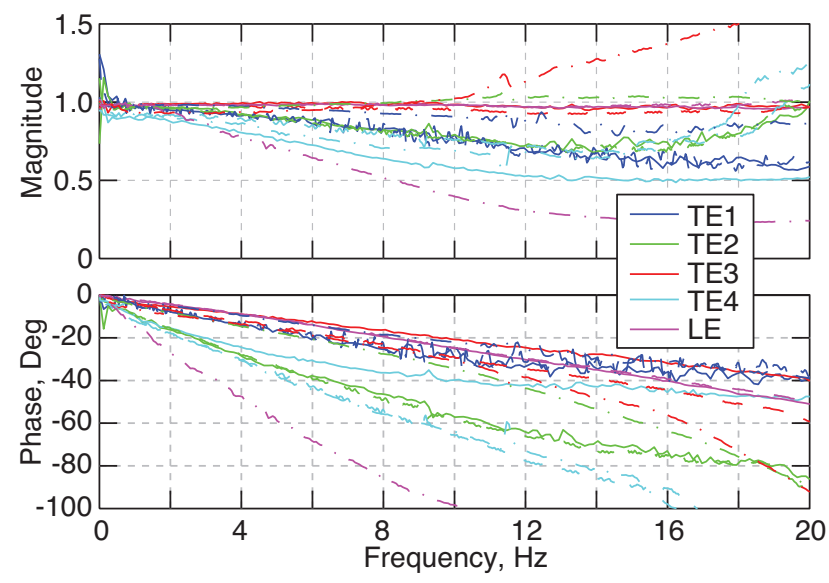

Fig. 22 Flap transfer function estimates for beginning (solid), middle (dash), and end (dot dash) of Test 598, Points 216, 1600, and 5409.

\section{Acknowledgements}

From Northrop Grumman the authors would like to acknowledge Tony Shimko for his expertise and guidance; Elaine Shaw for her tireless control design; test engineers, Lou Scherer, Chris Curnes and Kian Tehrani; and finally, Ted Schulman for much appreciated experience and insight.

From Lockheed Martin the authors would like to acknowledge Wink Baker and David White for their contributions to Test 598 that including model preparation, calibration, and wind-tunnel testing.

From NASA Langley Research Center the authors would like to acknowledge Chuck McClish for building the hydraulic manifold assembly; Patrice QuanderHaas and Gary Koepple for fabricating the snub control chassis, the moving mass controller, and their patience in dealing with ever changing requirements; Vic Tumwa for his assistance in conducting ground vibration tests; William Johnston and John Newman for performing the LAS spring fatigue test on such short notice; and Mike Ramey, Jeff Wilfong, and Anthony Pototzky for their assistance in conducting the windtunnel test.

Finally, we would like to acknowledge the design, fabrication, and test support efforts of NextGen Aeronautics including David Cowan, Matthew Scott, Dana Howard, Robert Alphenaar, Robert Myers, Jonathan Prouty, and Richard Guhr.

\section{Appendix A: Flap Actuator Response}

Due to the aeroservoelastic nature of these windtunnel tests, the frequency responses of the five flap actuators was important. The PID gains on the five control loops were established by examining one actuator-loop at a time while tracking a square wave command. Command and position are plotted in near real time on the dSpace1 host system. The procedure 
for setting the gains is to start with zero integral and derivative gains, and increase the proportional gain until actuator instability then back off approximately $20 \%$. The derivative gain is then adjusted to improve stability. This process is repeated until satisfactory response characteristics are obtained. Integral gain was not found to be effective and was generally set to zero.

Given the fact that GLA testing is quite demanding in terms of the actuator stroke requirements and the number of cycles, the flap actuators performance was satisfactory. This was especially true for Test 598 where many hours of trimmed flight was successfully demonstrated with the AOS operating. The actuators were, however, the highest maintenance items for Test 598, and three main problems were encountered. The first of these were leaks in the o-rings that seal the actuator shafts. They were a known wear item, and periodic replacement was expected. The other two problems were more troublesome. There was an issue with the end-cap o-ring seal where slight variations in the installation procedure and/or lot number variations in the o-rings could lead to part of the o-ring binding against the actuator shaft. This binding would limit actuator bandwidth and linearity, and could be identified by the flap position time trace having a distinctive clipped appearance. Finally, in terms of actuator performance, free play was the biggest problem. Since, the flap position sensor (RVDT) was not attached directly to the actuator shaft, but to the flap, any free play between the actuator shaft and the flap would interfere with the servo control loop.

As part of the start-of-day operations, data was acquired with a 30 second sine-sweep position command being applied to all five flaps. Command and position time histories were acquired, and the actuator transfer functions were estimated using the MatLab TFESTIMATE command. Transfer function estimates for the beginning, the middle, and the end of Test 598 are shown in figure 22. As can be seen, there was some variation in actuator transfer functions throughout the test with flaps TE2 and TE4 having chronic phase issues compared with the other surfaces due the inability to remove the free play.

Cross resonance in the model could also excite the actuator free-play in other actuators causing sympathetic limit cycles. In these cases, a reduced proportional gain was needed to maintain stability. By the end of the test, the LE actuator would enter a limit cycle above a dynamic pressure of $60 \mathrm{psf}$, and it had to be substantially detuned in order to maintain stability as indicated by the large phase lag.

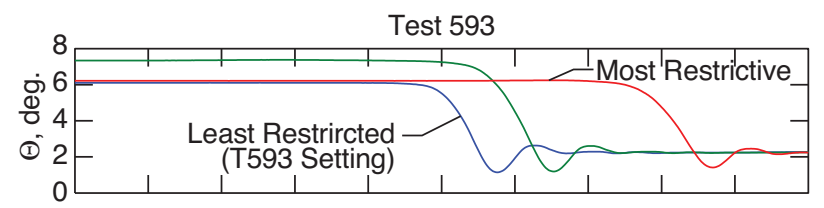

Test 598 Without Wing Installed
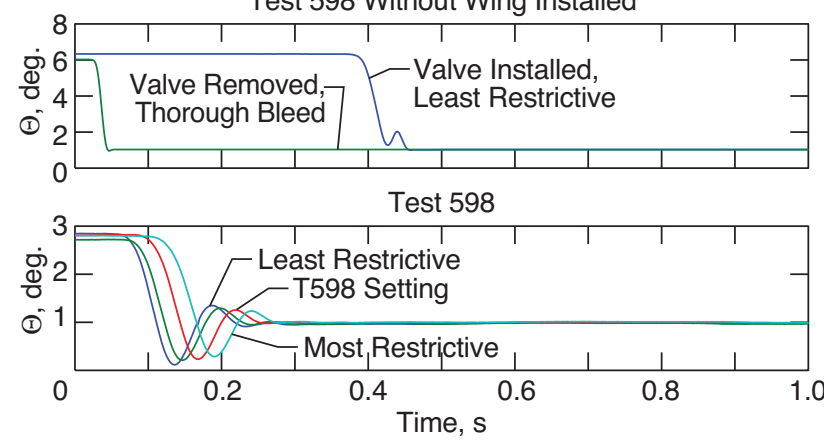

Fig. 23 Snubber system time delay experiments, hydraulics at 2000 psi.

\section{Appendix B: Snubbing System Performance}

The performance of the snubber system was an important consideration for the AEI wind-tunnel tests. Snubber performance data acquired during Test 593 and Test 598 will be discussed here. Figure 23 shows the evolution of the snubber system performance starting with data from Test 593, followed by some experiments from Test 598 buildup where the wing was not installed, and finally, data acquired at the start of Test 598. In all cases, pitch angle is plotted versus time, and these time traces are lined up such that the Snub! command for each was issued at $\mathrm{T}=0 \mathrm{~s}$.

Initial testing of the snubber system performance for Test 593 is shown in the upper part of figure 23. An adjustable flow rate valve was added to the hydraulic line feeding the snubber system to provide some control over the snub rate, and three flow rate settings were considered. Here, with the least restrictive valve setting, the time required to snub the model from the initiation of a Snub! command exceeded 0.5 seconds, and this setting was used in Test 593. It is interesting to note that these data were acquired when the snubber hydraulics were first installed, and no further timing studies were performed. However, subsequent and frequent operational usage of the snubber system may have resulted in some break-in as the operational snubs indicated a shorter time delay of about $0.3 \mathrm{sec}-$ onds. For example, data from the end of Test 593 is plotted in figure 12 where there appears to be about 0.3 seconds of delay between the Snub! command and theta being clamped.

In preparation for Test 598, the time delay between issuing a Snub! command and the pitch angle being limited and subsequently clamped was a concern. The center plot in figure 23 shows the results of some stud- 
ies of the snubber system prior to wing installation. The initial data set (blue) indicated a time delay similar to what was observed in Test 593. As a result, three possible fixes were considered, and they were the removal of the flow rate valve, a better method of bleeding the air out, and a diode installed across the solenoid electrical leads. As it turned out, the rotation of the pivot carriage assembly, discussed earlier, ended up being serendipitous as it facilitated bleeding the hydraulics. With the actuator in a vertical stroke position, air in the actuator would rise to the top. If the actuator was repeatedly cycled and bled, all the air from the system could be removed. A satisfactory result was finally obtained as indicated in the center figure.

Snubber timing studies of the system in the final Test 598 configuration are shown in the lower plot of figure 23. Here, the wing has been installed, the system has been thoroughly bled, and the flow rate valve was used. Several flow rate settings were investigated with the final Test 598 setting identified in the plot. The net time delay used in subsequent analysis and in the WatchDog system was estimated to be 0.15 seconds. The reason the flow rate valve was included was that engaging the snubber mechanism could, under some circumstances, induce wing bending loads near limit values. The final flow rate setting was a compromise between snubber speed and induced loads. One known circumstance worth mentioning was air-off snubber engagement. If the model was snubbed airoff with full hydraulic pressure, large bending loads would result. To avoid this problem, at the start of TDT operations, the model was electrically snubbed (solenoid valve open) prior to bringing the hydraulic pump on-line. As the initial set point for the pump was around 200 psf, the model could be brought to a snubbed state relatively slowly with minimal bending loads. The hydraulic pump would then be brought up to its operational pressure of 2,000 psi.

The snubbing system performed quite well throughout Test 598 with one minor exception. The solenoid valve must be energized to unsnub the system. Therefore, removing power to the solenoid valve snubs the model. There were several instances during both Test 593 and Test 598 when the snubber mechanism could not be unsnubbed as the valve had apparently stuck in the snubbed position. If the solenoid was left deenergized for approximately 30 minutes, it would start functioning properly again. Installation of a pancake fan to cool the solenoid coil and valve solved the problem during Test 598.

\section{Appendix C: Rail Friction and LAS}

The model and mount system contained a variety of unusual or high maintenance systems that were all critical to the success of Test 598. One critical area was the performance and longevity of the LAS and the friction associated with the mount system rails. These items will be discussed here.

Prior to Test 598, one area of concern was the potential for frequent replacement of the LAS springs. The time involved in clearing the R134a test medium from the TDT along with the time required to change the LAS springs would result in the loss of at least one day of test time. As the model would be flying as close to tunnel center line as possible, the center of the LAS springs would receive the most cycles, and data from Test 593 indicated that the vendor rated life of 13,000 cycles could be reached several times a week. To assess the level of conservatism in the vendors rated life, a fatigue test of the springs mounted in the LAS assembly was conducted using an Instron machine at NASA Langley Research Center. The springs were pulled out a distance of 12 in to be consistent with the configuration expected with the model flying at tunnel centerline, and the springs were cycled at \pm 1 inch at $1 \mathrm{~Hz}$. These tests indicated that the springs had a fatigue life of at least 98,000 cycles.

For Test 598, Lockheed Martin introduced the use of load cells to measure the LAS force in the lab, during TDT buildup, and during wind-tunnel testing. An additional load cell could be temporarily attached to the wing to measure the force required to lift the wing through its vertical range of motion. Reference 11 describes the extensive rail and LAS friction experiments performed during build-up in the TDT model preparation area. Based on these experiments, the LAS friction was determined to be about \pm 2.5 lbs per spring set (forward and aft) and the rail assembly friction was between \pm 11 and \pm 17 lbs. Once the wing, mount, and fairing were assembled in the final test configuration an abbreviated friction experiment was performed periodically to assess LAS and rail friction. This experiment consisted of acquiring load cell and vertical position data while lifting the wing via the third load cell through its vertical range of motion up and down. Data acquired at the start of Test 598 and after about 4 weeks of wind-tunnel testing is plotted in figure 24. These data indicated a hysteresis loop where force is dependent on the direction of motion. For the purposes of health monitoring, these data were examined for consistency. The data acquired at point 3237 was deemed satisfactory and the wind-tunnel test was continued.

The LAS load cell data was acquired by the DAS and monitored by the test engineers during wind-tunnel testing. LAS load cell data plotted versus wing vertical position is shown for three different take-off and subsequent trimmed flights in figure 25. The data from point 3245 indicates a healthy LAS system. Closer ex- 

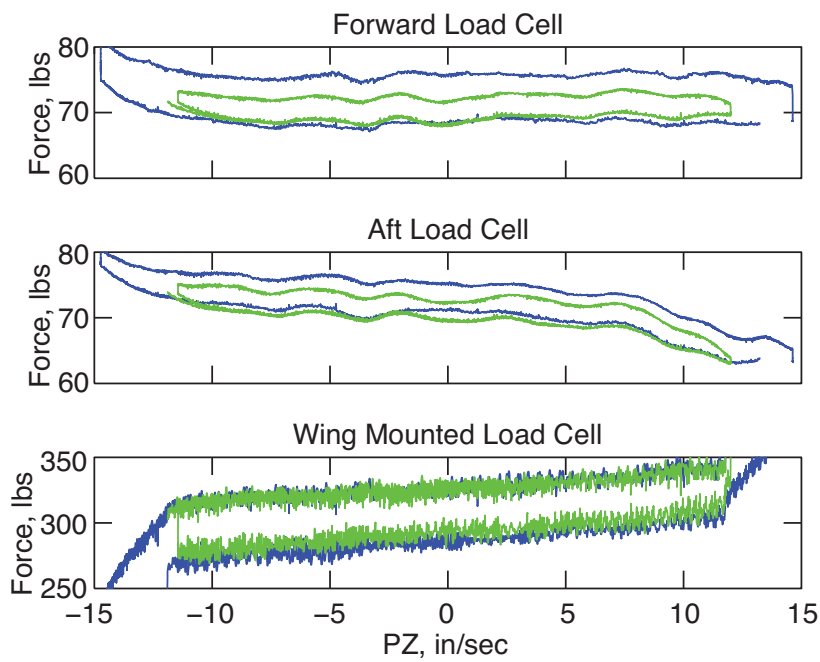

Fig. 24 LAS and wing mounted load cell moving average data acquired during wing vertical translation. Test 598, Points 212 (blue) and 3237 (green).
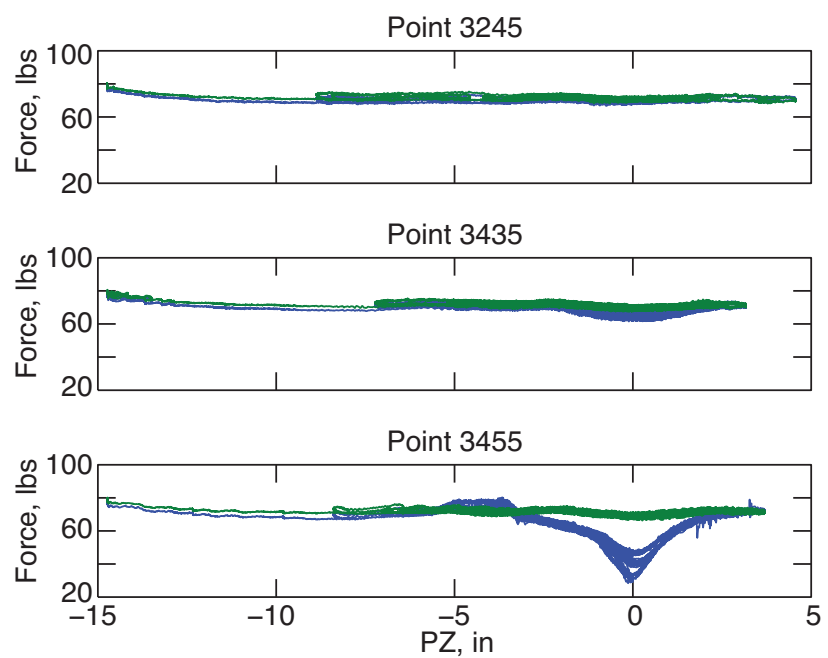

Fig. 25 LAS load cell data acquired during three different takeoff and flight sequences. Test 598, Points 3245, 3435, and 3455. (Forward load cell data is blue and the aft load cell data is green).

amination of this data indicates that during flight, the LAS friction is no more than $\pm 1.5 \mathrm{lbs}$, less than what was measured air-off. The higher vibration environment associated with wind-on operations may improve LAS performance in this regard. The next two data points indicated a weakening and failed, respectively, forward LAS spring assembly. The LAS system failed twice during Test 598. The first failure was at the point shown here near the middle of the test. During repair of the LAS system, the model was changed to the light weight configuration. The LAS also failed on the final day of testing.

\section{Appendix D: Development of LM Combined Parameters}

A significant analysis effort was undertaken by Lockheed Martin Aeronautics to determine additional WatchDog parameters so that a Snub! command would be issued in time to snub the model and subsequently control plunge displacement using the emergency controller before the pivot carriage hit the dampers. These combined parameters needed to take into account the time delay in physically snubbing the model and vertical travel needed by the emergency controller to obtain a zero sink rate. This appendix will describe how the LM combined parameters were developed, verified, and implemented.

A simulation model of the wing, mount system, and control systems was developed in MatLab Simulink. The wing, including the mass of the pivot carriage assembly, was modeled using a series of state-space models for various combinations of Mach number and dynamic pressure with two-dimensional interpolation used to generate the ASE model used at a given flight condition. The ASE model contained inputs for 5 control surface position commands, and a vertical gust velocity input. The physical constraints and forces associated with the rest of the mount system were imposed on the wing root using 6 force/moment inputs ( $\mathrm{x}, \mathrm{y}, \mathrm{z}$, roll, pitch, yaw). The effects of mount flexibility were modeled using these force terms. In the case of the vertical force, terms for friction as a function of bending moment, the LAS, the damper, and the hard stop were included. The pitch moment force included terms for the pitch dampers, hard stop, and the pitch clamp actuator. The outputs of the ASE model were the 23 aircraft sensors.

A series of simulations were run to determine the relationship between the initial condition of the model and vertical travel needed to obtain a zero sink rate. The simulation started with an initial vertical rate, pitch angle, pitch rate, and dynamic pressure for both the heavy and light model configurations The initial conditions for all other parameters were assumed to be zero. The time delay between Snub! command and a pitch restoring force being applied to the wing root was also assumed to be zero. The simulation studies indicated that if the model was not snubbed at the time of pivot carriage to damper contact, large pitch excursions and wing bending moments would result. Thus, wing bending moments were within allowable limits as long as the model was snubbed prior to vertical damper contact. The simulation data was then used to construct a new WatchDog parameter. The parameter was generated by determining the relationship between vertical velocity, pitch angle, and dynamic pressure and the vertical distances up or down needed to stop the model once the snubber had been engaged. This 


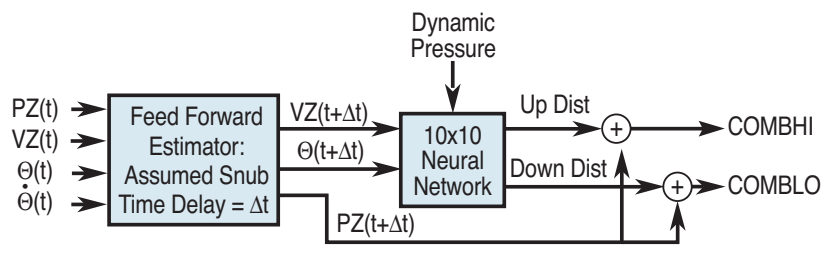

Fig. 26 Lockheed Martin combined parameter block diagram.

mathematical relationship was represented by a 10 by 10 neural network.

In order to account for any time delay between the Snub! command and pitch snub mechanism physical engagement, some parameters were extrapolated into the future. A simple feed forward estimation routine using an assumed snubber time delay was applied to vertical position, vertical rate, pitch angle, and pitch rate. The forward estimator and neural network were combined in series in the WatchDog system as shown in figure 26 to provide a real-time estimate of the vertical position, up or down, where the model would be brought under control. These values were monitored by the WatchDog system, and as with the other monitored signals, the WatchDog would issue a Snub! command when thresholds were exceeded.

To assess snubber time delay requirements, 5 hard landing cases from Test 593 were examined. For one of these data points, time histories of vertical position, pitch angle, Snub! command, trailing edge surface 2 command, and wing root bending moment are plotted in figure 27. Here, it can be seen that the model starts to climb then falls back, lands hard, and bounces. Pitch angle and bending moment decrease rapidly after contacting the damper just before $\mathrm{T}=42 \mathrm{~s}$ where slope discontinuities are observed in the vertical position, pitch angle, and bending moment time histories. These data are consistent with the simulation results indicating the need to have the model clamped in pitch prior to damper contact to minimize subsequent pitch angle excursions and high wing bending loads.

Table 2 WatchDog performance assessed using 5 hard landing cases from Test 593.

\begin{tabular}{|c|c|c|c|}
\hline $\begin{array}{c}\text { Assumed } \\
\text { Snub } \\
\text { Time }\end{array}$ & $\begin{array}{c}\text { Required } \\
\text { Time } \\
\text { Delay }\end{array}$ & \multicolumn{2}{|c|}{ WD Performance } \\
\hline Delay & (pt. 1252) & In-Time & False Alarm \\
\hline & 0.065 & $2 / 5$ & $1 / 5$ \\
\hline 0.10 & 0.113 & $5 / 5$ & $0 / 5$ \\
\hline 0.25 & 0.165 & $2 / 5$ & $1 / 5$ \\
\hline
\end{tabular}

For the 5 hard landing cases, the performance of the WatchDog system monitoring only the original measured parameters was compared with the WatchDog system configured to monitor the LM combined

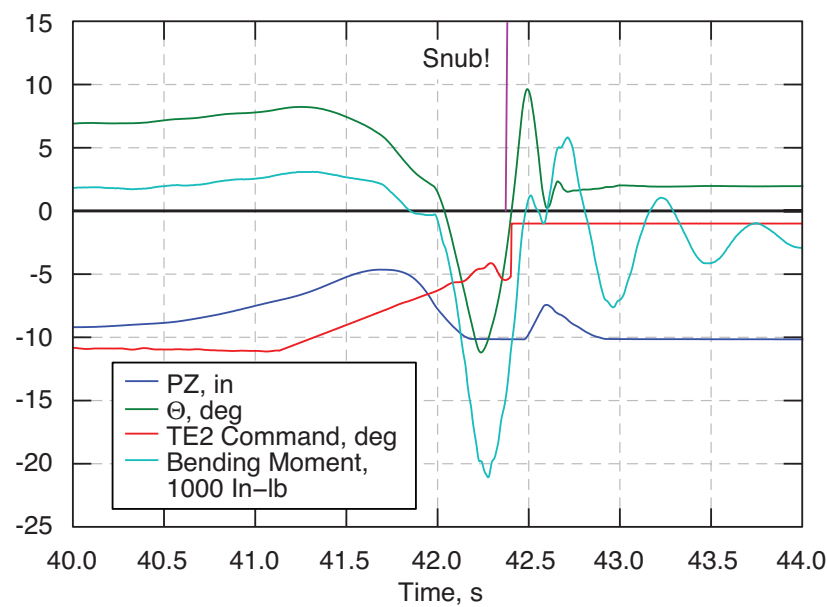

Fig. 27 Hard landing case plot of vertical position and model angle with damper contact and Snub! command. Test 593, Point 1252. The bending moment is measured from strain gauge SBI1 shown in figure 8 corrected for outboard wing weight.

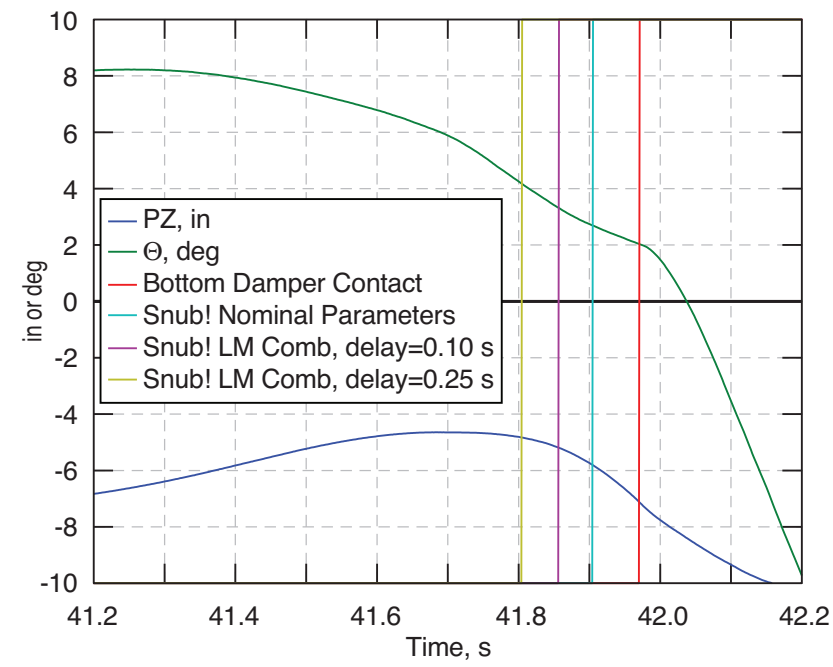

Fig. 28 Hard landing case comparing nominal WatchDog performance with and without combined parameters. Test 593, Point 1252.

parameter using two different assumed snubber time delays of 0.1 and 0.25 seconds. One of these hard landing cases is shown in figure 28 where the model vertical position and pitch angle are plotted along with the Snub! command associated with the three WatchDog configurations. Damper contact time is indicated by the red line. For this data, the original WatchDog system would have snubbed the model as it was descending through a $-10 \mathrm{inch} / \mathrm{sec}$ velocity threshold. The combined parameter cases caught the model earlier, as shown. The figure of merit for these cases is the time difference between damper contact and when the command was issued. If the actual, physical snubber time delay is less than the required time delay, then a 
given WatchDog parameter would have been successful in avoiding model and damper contact and high loads. Required time delay for the data shown in figure 28 along with a summary of the performance of the WatchDog parameters for all 5 Test 593 cases examined is shown in table 2. A false alarm is defined as a case where a Snub! command is issued, but the bending load limits were not subsequently exceeded in the data set. The combined parameter with an assumed 0.1 second snubber time delay was able to snub the model before contacting the damper in all 5 cases with no false alarms. As previously discussed, the physical snubber system was ultimately configured to provide a delay of 0.15 seconds.

\section{References}

${ }^{1}$ Martinez, J., "An overview of SensorCraft capabilities and key enabling technologies," 26th AIAA Applied Aerodynamics Conference, No. AIAA-2008-7185, Honolulu, Hawaii, Aug. 2008.

${ }^{2}$ Reichenbach, E., "Aeroservoelastic Design and Test Validation of the Joined Wing Sensorcraft," 26th AIAA Applied Aerodynamics Conference, No. AIAA-2008-7189, Honolulu, Hawaii, Aug. 2008.

${ }^{3}$ LeDoux, S., Vassberg, J., and Fatta, G., "Aerodynamic Cruise Design of a Joined Wing SensorCraft," 26th AIAA Applied Aerodynamics Conference, No. AIAA-2008-7190, Honolulu, Hawaii, Aug. 2008.

${ }^{4}$ Lockyer, A. J., Drake, A., Bartley-Cho, J., Vartio, E., Solomon, D., and Shimko, T., "HIGH LIFT OVER DRAG ACTIVE (HiLDA) WING; Delivery Order 0007: HiLDA Wing Program," Tech. Rep. AFRL-VA-WP-TR-2005-3066, Northrop Grumman Corporation, 2005.

${ }^{5}$ Vartio, E., Shimko, A., Tilmann, C. P., and Flick, P. M., "Structural Modal Control and Gust Load Alleviation for a SensorCraft Concept," 46th AIAA/ASME/ASCE/AHS/ASC Structures, Structural Dynamics and Materials Conference, No. AIAA-2008-7185, Austin, Texas, April 2005.

${ }^{6}$ Silva, W., Vartio, E., Shimko, A., Kvaternik, R. G., Eure, K. W., and Scott, R. C., "Development of Aeroservoelastic Analytical Models and Gust Load Alleviation Control Laws of a SensorCraft Wind-Tunnel Model Using Measured Data," 47th AIAA/ASME/ASCE/AHS/ASC Structures, Structural Dynamics and Materials Conference, No. AIAA2006-1935, Newport, Rhode Island, May 2006.

${ }^{7}$ Staff of the Aeroelasticity Branch, "The Langley Transonic Dynamics Tunnel," Langley Working Paper LWP-799, Sept. 1969.

${ }^{8}$ Corliss, J. M. and Cole, S. R., "Heavy Gas Conversion of the NASA Langley Transonic Dynamics Tunnel," Proceedings of the 20th Advanced Measurements and Ground Testing Technology Conference, No. 98-2710, Albuquerque, NM, June 1998.

${ }^{9}$ Cole, S. R. and Rivera Jr, J. A., "The New Heavy Gas Testing Capability in the NASA Langley Transonic Dynamics Tunnel," Royal Aeronautical Society Wind Tunnels and Wind Tunnel Test Techniques Forum, No. 4, Cambridge, UK, April 1997.

${ }^{10}$ Bartley-Cho, J. and Henderson, J., "Design and Analysis of HiLDA/AEI Aeroelastic Wind Tunnel Model," 26th AIAA Applied Aerodynamics Conference, No. AIAA-2008-7191, Honolulu, Hawaii, Aug. 2008.

${ }^{11}$ Love, M. H. and et. al., "Final Report for the Aerodynamic Efficiency Improvement Contract No.: FA8650-05-C3501," Tech. Rep. FMZ-9454, Lockheed Martin Corporation, 2008 .
${ }^{12}$ Mangalam, S. and Mangalam, A., "Unsteady Aerodynamic Observable for Gust Load Alleviation and Flutter Suppression," 26th AIAA Applied Aerodynamics Conference, No. AIAA-20087187, Honolulu, Hawaii, Aug. 2008.

${ }^{13}$ Perry, B., Cole, S. R., and Miller, G. D., "Summary of an Active Flexible Wing Program," AIAA Journal of Aircraft, Vol. 32, No. 1, 1995, pp. 10-15.

14 "http://www.bbc.co.uk/science/humanbody/sleep/sheep/," BBC Homepage, Science \& Nature: Human Body \& Mind, Sheep Dash! A simple on-line game testing human reaction time.

${ }^{15}$ McDowell, M. M., "A Controlled Study on Batted Ball Speed and Available Pitcher Reaction Time in Slowpitch Softball," British Journal of Sports Medicine, Vol. 39, 2005, pp. $223-225$.

16 "Sanchez v. Hillerich \& Bradsby Co." Court of Appeal, Second District, Division 4, California, 2002, http://www.napil.com/PersonalInjuryCaseLawDetail31772.htm.

${ }^{17}$ Vartio, E. and Shaw, E., "GLA Flight Control System Design for a SensorCraft Vehicle," 26th AIAA Applied Aerodynamics Conference, No. AIAA-2008-7192, Honolulu, Hawaii, Aug. 2008.

${ }^{18}$ Larimore, W. E., "Optimal Order Selection and Efficiency of Canonical Variate Analysis System Identification," Proc. 13 IFAC World Congress, San Francisco, California, July 1996.

${ }^{19}$ Penning, K., Zink, P. S., Wei, P., De La Garza, A. P., and Love, M. H., "GLA and Flutter Suppression for a SensorCraft Class Concept Using System Identification," 26th AIAA Applied Aerodynamics Conference, No. AIAA-2008-7188, Honolulu, Hawaii, Aug. 2008. 